\title{
MTH1, an oxidized purine nucleoside triphosphatase, protects the dopamine neurons from oxidative damage in nucleic acids caused by 1-methyl-4-phenyl-1,2,3,6- tetrahydropyridine
}

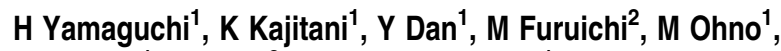 \\ $\mathrm{K}$ Sakumi ${ }^{1}$, D Kang ${ }^{3}$ and $Y$ Nakabeppu ${ }^{\star, 1}$ \\ 1 Division of Neurofunctional Genomics, Department of Immunobiology and \\ Neuroscience, Medical Institute of Bioregulation, Kyushu University, Fukuoka \\ 812-8582, Japan \\ 2 Radioisotope center, Kyushu University, Fukuoka 812-8582, Japan \\ ${ }^{3}$ Department of Clinical Chemistry and Laboratory Medicine, Graduate School \\ of Medical Sciences, Kyushu University, Fukuoka 812-8582, Japan \\ * Corresponding author: Y Nakabeppu, Division of Neurofunctional Genomics, \\ Department of Immunobiology and Neuroscience, Medical Institute of \\ Bioregulation, Kyushu University, 3-1-1 Maidashi Higashi-ku, Fukuoka, 812- \\ 8582, Japan. Tel: + 8192642 6800; Fax: + 81926426791 ; \\ E-mail: yusaku@bioreg.kyushu-u.ac.jp
}

Received 17.6.05; revised 30.8.05; accepted 30.8.05; published online 4.11.05 Edited by $\mathrm{H}$ Ichijo

\section{Abstract}

We previously reported that 8-oxoguanine (8-oxoG) accumulates in the cytoplasm of dopamine neurons in the substantia nigra of patients with Parkinson's disease and the expression of MTH1 carrying an oxidized purine nucleoside triphosphatase activity increases in these neurons, thus suggesting that oxidative damage in nucleic acids is involved in dopamine neuron loss. In the present study, we found that levels of 8-oxoG in cellular DNA and RNA increased in the mouse nigrostriatal system during the tyrosine hydroxylase (TH)-positive dopamine neuron loss induced by the administration of 1-methyl-4-phenyl-1,2,3,6-tetrahydropyridine (MPTP). MTH1-null mice exhibited a greater accumulation of 8-OxOG in mitochondrial DNA accompanied by a more significant decrease in $\mathrm{TH}$ and dopamine transporter immunoreactivities in the striatum after MPTP administration, than in wild-type mice. We thus demonstrated that MTH1 protects the dopamine neurons from oxidative damage in the nucleic acids, especially in the mitochondrial DNA of striatal nerve terminals of dopamine neurons.

Cell Death and Differentiation (2006) 13, 551-563.

doi:10.1038/sj.cdd.4401788; published online 4 November 2005

Keywords: MPTP; 8-oxoguanine; Parkinson's disease; mitochondria; striatum

Abbreviations: 2-OH-dATP, 2-hydroxy-2'-deoxyadenosine triphosphate; 8-oxo-dGTP, 8-oxo-2'-deoxyguanosine triphosphate; 8-oxo-dG, 8-oxo-2'-deoxyguanosine; 8-oxoG, 8-oxoguanine; $A D$, Alzheimer's disease; DAT, dopamine transporter; dG, 2'-deoxyguanosine; GFAP, glial fibrillary acidic protein; mAb, monoclonal antibody; $\mathrm{MPP}^{+}$, 1-methyl-4-phenylpryridinium; MPTP, 1-methyl-4-phenyl-1,2,3,6-tetrahydropyridine; NAc, nucleus accumbens; OT, olfactory tubercle; PD, Parkinson's disease; SN, substantia nigra; SNc, substantia nigra pars compacta; $\mathrm{SNr}$, substantia nigra pars reticulata; TH, tyrosine hydroxylase; VTA, ventral tegmental area; VDAC, voltage-dependent anion-selective channel

\section{Introduction}

The accumulation of oxidative damage in cellular DNA or RNA, which is one of major causes for mutagenesis and cell death during aging, is a result of the incorporation of the oxidized nucleotides generated in nucleotide pools as well as a result of their direct oxidation. ${ }^{1}$ To minimize the incorporation of oxidized nucleotides into cellular DNA or RNA, organisms normally come equipped with an elaborate mechanism to sanitize the nucleotides pools. In Escherichia coli, MutT hydrolyzes 8-oxo-2'-deoxyguanosine triphosphate (8-oxo-dGTP) and 8-oxo-GTP to monophosphate forms thereby avoiding the misincorporation of such mutagenic nucleotides into DNA or mRNA. ${ }^{2}$ We identified MutT homologues in human and rodent cells and they were found to suppress the elevated spontaneous mutation rates of mutT mutants to an almost normal level, and they were thus designated as MTH1 (MutT homolog-1). ${ }^{2,3}$ MTH1, but not E. coli MutT, has an ability to efficiently hydrolyze oxidized dATP and ATP, such as 2-hydroxy-2'-deoxyadenosine triphosphate (2OH-dATP), and 2-OH-ATP, as well as 8-oxo-dGTP or 8oxoGTP, and thus designated MTH1 as an oxidized purine nucleoside triphosphatase. ${ }^{3,4}$

It has been established that oxidative DNA damage, such as 8-oxoguanine (8-oxoG), accumulates both in nuclear and mitochondrial genomes during aging, ${ }^{5,6}$ and such accumulation is likely to increase dramatically in patients with tumors ${ }^{7}$ or various neurodegenerative diseases, such as Parkinson's disease (PD), ${ }^{8,9}$ Alzheimer's disease (AD) ${ }^{10}$ or amyotrophic lateral sclerosis. ${ }^{11}$ We have shown that a significant increase of 8-oxoG accumulated in the cytoplasm or mitochondria with a coincidentally elevated expression of MTH1 in the substantia nigral neurons of PD patients. ${ }^{9}$ In postmortem tissue specimens from patients with $A D$, the expression levels of MTH1 in the entorhinal cortex were also elevated, while the levels of MTH1 apparently decreased in the stratum lucidum at CA3 corresponding to the mossy fiber synapses, where MTH1 is highly expressed in control subjects. ${ }^{12}$ These observations strongly suggest that MTH1 plays an important role in protecting neurons from oxidative damage.

To characterize the biological importance of MTH1, we established MTH1-null mice and found them to exhibit an increased occurrence of spontaneous carcinogenesis especially in the liver, and to a lesser extent in the lung and 
stomach. ${ }^{13}$ We recently reported that MTH1-null fibroblasts were highly susceptible to cell dysfunction and death caused by exposure to $\mathrm{H}_{2} \mathrm{O}_{2}$, with morphological features of pyknosis and electron dense deposits accumulated in the mitochondria, accompanied by a continuous accumulation of 8-oxoG both in nuclear and mitochondrial DNA. ${ }^{14}$ All of the $\mathrm{H}_{2} \mathrm{O}_{2}$-induced alterations observed in MTH1-null fibroblasts were effectively suppressed by the expression of wild-type human MTH1, thus demonstrating that $\mathrm{MTH} 1$ indeed protects cells from oxidative damage.

In the present study, we show that the levels of 8-oxoG in cellular DNA and RNA increased in the mouse nigrostriatal system during the dopamine neuron loss induced by the systemic administration of 1-methyl-4-phenyl-1,2,3,6-tetrahydropyridine (MPTP). Moreover, MTH1-null mice exhibited an increased accumulation of 8-oxoG in mitochondrial DNA in the striatum followed by a more significant neuronal dysfunction after MPTP administration, in comparison to wild type.

\section{Results}

\section{Spontaneous oxidative damage in nucleic acids of normal mouse brain}

To evaluate the spontaneous levels and distributions of the oxidative damage of nucleic acids in normal mouse brain, the levels of 8-oxoG in cellular DNA and RNA were analyzed. Brain sections were subjected to immunohistochemistry with two different monoclonal antibodies (mAbs) which preferentially react with either 8-oxoG in DNA (N45.1) or RNA (15A3) using proper pretreatments.

In samples pretreated with RNase and $\mathrm{HCl}$, the $\mathrm{N} 45.1 \mathrm{mAb}$ exhibited nuclear immunoreactivities mostly in neurons throughout the brain including the hippocampus (Figure $1 \mathrm{Aa}, \mathrm{c})$ and substantia nigra (SN) (Figure 1Ab, d). These immunoreactivities were abolished by either the pretreatment of the sections with DNase (Figure $1 \mathrm{Ae}, \mathrm{f}$ ) or the preadsorption of the antibody with 8-oxo-dG (Figure 1Ag, h) but not 2 -deoxyguanosine $(\mathrm{dG})$ (Figure $1 \mathrm{Ai}, \mathrm{j})$, thus indicating that guanine residues in the nuclear DNA of neurons are spontaneously oxidized to some extent. We also measured the 8-oxoG levels in nuclear DNA prepared from various regions of mouse brain by HPLC-MS/MS method (Table 1). About 2.5-3 residues of 8-oxoG per $10^{6}$ guanine residues were present in the nuclear DNA from the cerebrum, cerebellum, other brain region that contains striatum, thalamus and brainstem, and the liver from control wild-type and MTH1-null mice.

In samples without any pretreatment, in contrast, the $15 \mathrm{~A} 3 \mathrm{mAb}$ exhibited cytoplasmic immunoreactivities in the whole brain region including the cerebral cortex, hippocampus (Figure 1Ba, c) and SN (Figure 1Bb, d), and again these immunoreactivities were abolished by either the pretreatment of sections with RNase (Figure $1 \mathrm{Be}, \mathrm{f}$ ) or the preadsorption of the antibody with 8-oxo-dG (Figure 1Bg, h) but not dG (Figure $1 \mathrm{Bi}, \mathrm{j})$. These results indicate that there are substantial levels of spontaneously oxidized guanine in cellular RNA.

In samples pretreated only with RNase, the N45.1 mAb exhibited weak cytoplasmic or perinuclear immunoreactivities in the neurons (Figure 1C), and these immunoreactivities were mostly merged with immunoreactivities to antibodies against the mitochondrial protein, voltage-dependent anionselective channel (VDAC) (Figure 1Cc, d). These findings indicate that guanine residues in the mitochondrial DNA in neurons are also spontaneously oxidized.

\section{Systemic administration of MPTP caused accumulation of 8-oxoG in cellular DNA and RNA in dopamine neurons in the nigrostriatal system}

We and others have shown that the 8-oxoG content in cellular DNA and RNA significantly increased in SN neurons in patients with PD. ${ }^{8,9}$ To address whether the levels of oxidative damage of nucleic acids in the neurons increase during dopamine neuron loss, we focused on the MPTP-induced PD mouse model.

Mice were injected intraperitoneally (i.p.) with MPTP $(30 \mathrm{mg} / \mathrm{kg})$, and then were killed $6,12,24 \mathrm{~h}$ after the injection, or $54 \mathrm{~h}$ after the first injection with three consecutive injections every $24 \mathrm{~h}$ (Figure $2 \mathrm{~A}$ ). at $6 \mathrm{~h}$ after MPTP injection, neither a decrease of tyrosine hydroxylase (TH) immunoreactivitiy, which is a phenotypic marker for dopamine neurons, nor an increase of 8-oxoG immunoreactivities in RNA and DNA was seen in the SN (data not shown). At $12 \mathrm{~h}$ after MPTP injection, a decrease of $\mathrm{TH}$ immunoreactivitiy was not seen yet (Figure 2Ba, b), however, an increased microglial activation, characterized by an amoeboid morphology with an increase in the expression of the CD11b detected by Mac-1 antibody, was observed in the SN pars compacta (SNc) (Figure 2Be, f). Thereafter, 8-oxoG immunoreactivitiy both in DNA and RNA in SN apparently increased (Figure 2Bi-l, $m-p)$. At $24 \mathrm{~h}$ after the first MPTP injection, a decrease of TH immunoreactivitiy, thus indicating dopamine neuron loss, was still not apparent (Figure 2Bc), however, $54 \mathrm{~h}$ later after three MPTP injections, the loss became highly prominent (Figure $2 \mathrm{Bd}$ ), and accompanied with more activated microglias (Figure 2Bg, h).

To compare the extent of 8-oxoG accumulation in RNA in neurons in the SNc and SN pars reticulata (SNr) after MPTP injection, the immunoreactivities for 8-oxoG in each region were separately digitized from the data shown in Figure $2 \mathrm{~B}$ $(m-p)$, and the level of 8-oxoG in each sample was determined. At $12 \mathrm{~h}$ after the first MPTP injection, the contents of 8-oxoG in the cellular RNA both in the $\mathrm{SNc}$ and $\mathrm{SNr}$ increased to about $140-150 \%$ of the levels seen in the control, and thereafter gradually decreased following the second and third injections (Figure 2C).

In order to confirm that the 8-oxoG immunoreactivities increased in dopamine neurons in the $\mathrm{SN}$, we performed double-immunofluorescence microscopy using anti-TH and anti-8-oxoG (15A3). The increase of 8-oxoG immunoreactivitiy in RNA $12 \mathrm{~h}$ after MPTP injection was apparently observed in most of the TH-positive dopamine neurons in the $\mathrm{SNc}$ (Figure 3A).

The 8-oxoG immunoreactivitiy in the nuclear DNA of THpositive dopamine neurons in the SNc was determined by laser scanning confocal microscopy. In the control, 8-oxoG immunoreactivitiy in the nuclei of $\mathrm{TH}$-positive neurons was apparently lower than that in the nuclei of the surrounding 


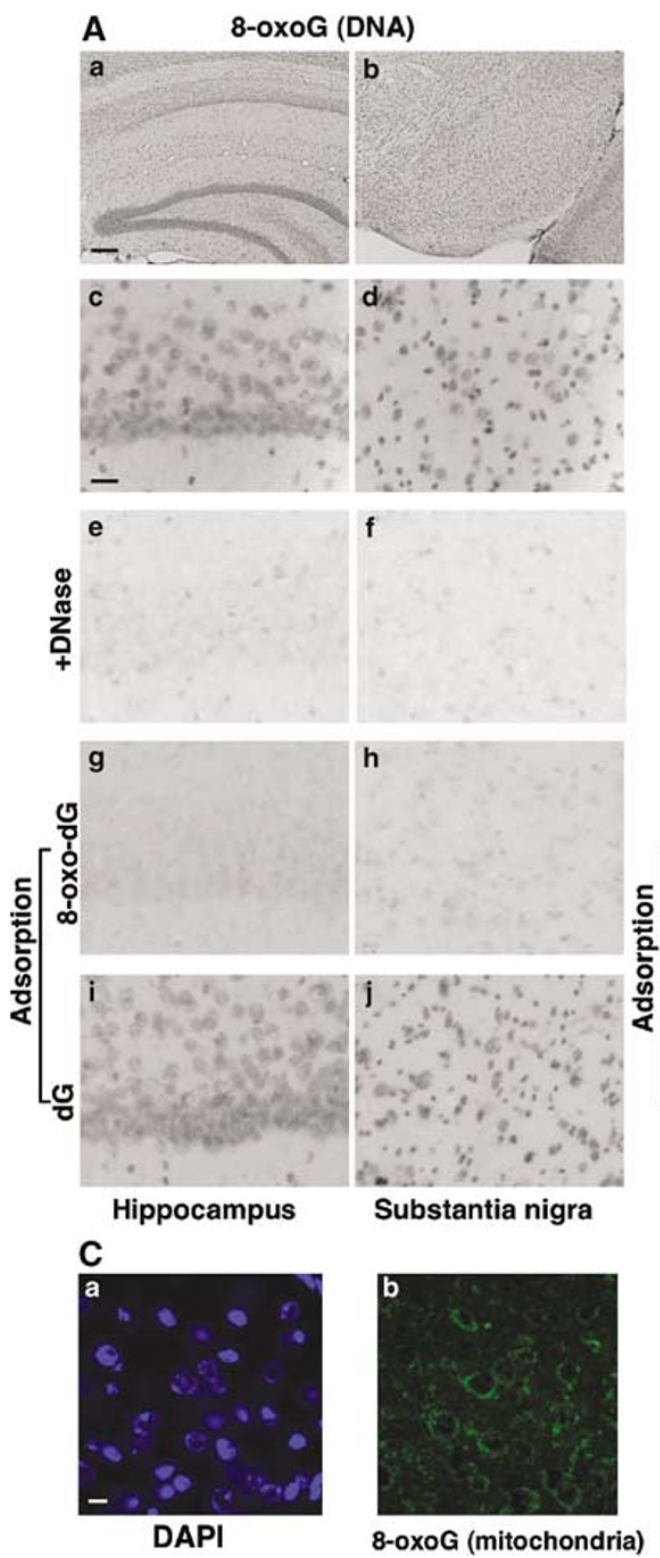

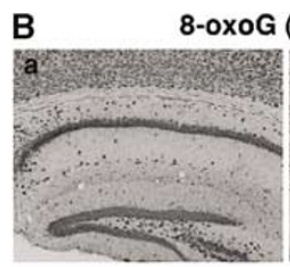
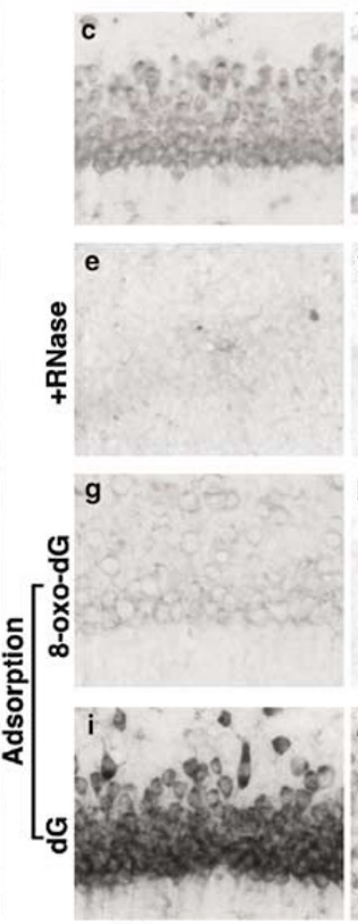

Hippocampus

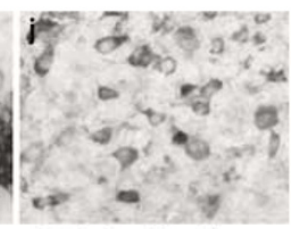

Substantia nigra

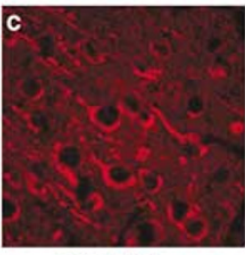

VDAC

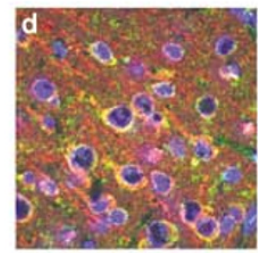

Merged

Figure 1 Spontaneous oxidative damage in nucleic acids of normal mouse brain. (A) Detection of 8-oxoG in cellular DNA. The sections prepared from 10-week-old $\mathrm{C} 57 \mathrm{BL} / 6 \mathrm{~J}$ male mice were subjected to immunohistochemistry with the $\mathrm{N} 45.1 \mathrm{mAb}$ after RNase and $\mathrm{HCl}$ treatment. The sections pretreated with DNase (e, f) exhibited little reactivity with the antibody, and preadsorption of the antibody with 8-oxo-dG $(\mathrm{g}, \mathrm{h})$ but not with $\mathrm{dG}(\mathrm{i}, \mathrm{j})$ abolished the immunoreactivitiy. Hippocampus (a, c, e, g, i), SN (b, d, f, h, j). Scale bars: $a-b, 200 \mu \mathrm{m} ; \mathrm{c}-\mathrm{i}, 20 \mu \mathrm{m}$. (B) Detection of 8-oxo-G in cellular RNA. The sections were subjected to immunohistochemistry with the 15A3 mAb without pretreatment. Cytoplasmic immunoreactivities were observed mostly in the neurons of hippocampus $(a, c)$ and SN (b, d). The sections pretreated with RNase $(\mathrm{e}, \mathrm{f})$ exhibited little reactivity with the antibody, and preadsorption of the antibody with 8-oxo-dG $(\mathrm{g}, \mathrm{h})$ but not with $\mathrm{dG}(\mathrm{i}, \mathrm{j})$ abolished the immunoreactivitiy. (C) Detection of 8-OxoG in the mitochondrial DNA. The sections were subjected to immunohistochemistry with the N45.1 mAb after RNase treatment. Laser-scanned confocal images from the cerebral cortex stained for nuclear DNA with DAPI (a), 8-oxoG (b), VDAC (c), and merged image (d) were shown. Weak perinuclear immunoreactivities for 8-oxoG were observed in large neurons (b), and these immunoreactivities were mostly merged with the mitochondrial protein VDAC immunoreactivitiy (c, d). Scale bar: $10 \mu \mathrm{m}$

TH-negative cells (Figure 3Ba), while the nuclear immunoreactivitiy in the $\mathrm{TH}$-positive neurons significantly increased $54 \mathrm{~h}$ after MPTP administration (Figure 3Bb). The fluorescence intensity for 8-oxoG immunoreactivitiy was digitized and the level of 8-oxoG in each sample was determined (Figure 3C). The content of 8-oxoG in the nuclear DNA in the $\mathrm{TH}$-positive neurons in the SNc increased gradually to the $140 \%$ level seen in the control during the $24 \mathrm{~h}$ period after the first MPTP injection, and thereafter gradually decreased following the second and third injections.

We next examined the extent of $\mathrm{TH}, \mathrm{CD} 11 \mathrm{~b}$, glial fibrillary acidic protein (GFAP) and 8-oxoG immunoreactivities in the striatum after MPTP administration. At $12 \mathrm{~h}$ after MPTP injection, a decrease in $\mathrm{TH}$ immunoreactivitiy indicating terminal dysfunction of dopamine neurons was apparent (Figure 4B), and an increased microglial activation was also 
A

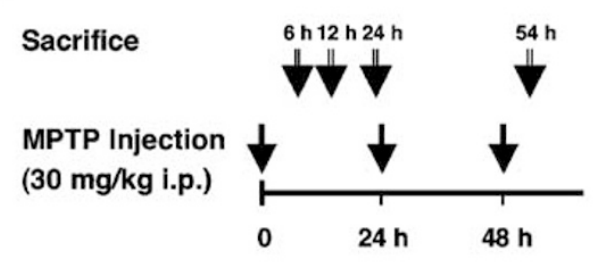

C

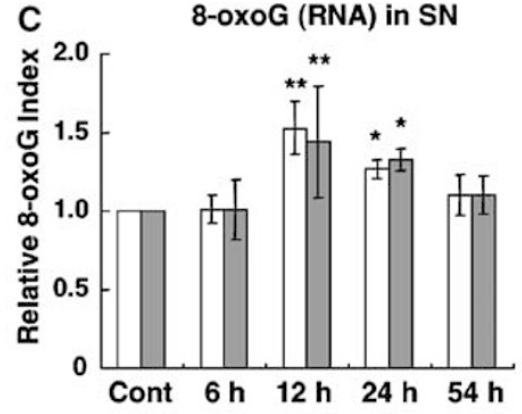

B

TH

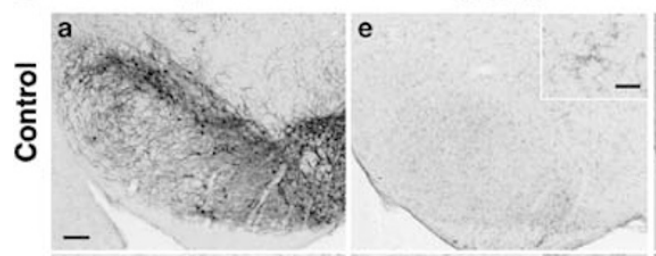

\section{CD11b}

8-OxOG (DNA)

8-OXOG (RNA)
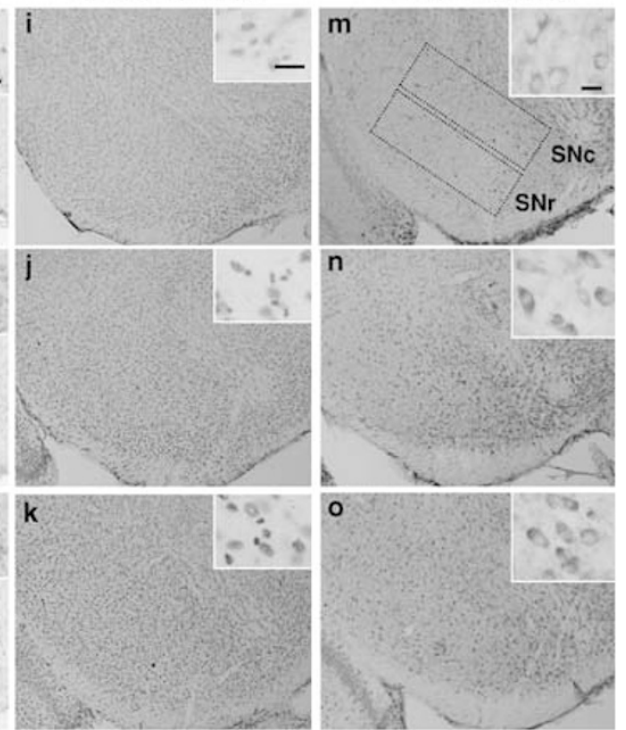

h
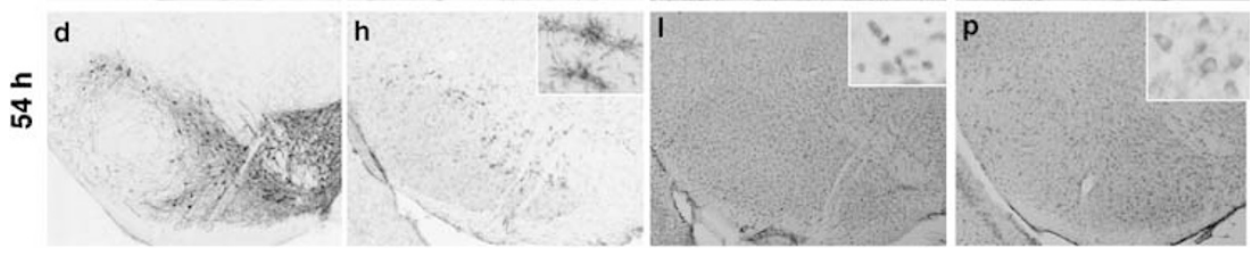

Figure 2 Systemic administration of MPTP increased the accumulation of 8-oxoG in nuclear DNA and cellular RNA of dopamine neurons in the substantia nigra prior to their loss. (A) 10-week-old C57BL/6J male mice ( $n=4$ per group) were injected i.p with MPTP (30 mg/kg). The mice received a single injection of MPTP were killed 6, 12, $24 \mathrm{~h}$ after the injection, and those received three injections of MPTP were killed $54 \mathrm{~h}$ after the first injection. (B) Immunohistochemical detection of TH (a-d), CD11b (eh), 8-0xoG in DNA (i-l) and 8-0xoG in RNA ( $m-p)$. Control mice $(a, e, i, m) ; 12 \mathrm{~h}$ after the first MPTP injection $(b, f, j, n) ; 24 \mathrm{~h}$ after the first injection (c, $\mathrm{g}, \mathrm{k}, 0) ; 54 \mathrm{~h}$ after the first injection with three injections of MPTP (d, h, I, p). Insets in panels (e-p) indicate enlarged view of each section. Scale bars (a-p), $200 \mu \mathrm{m}$; inset, $20 \mu \mathrm{m}$. (C) The increased accumulation of 8-0xoG in cellular RNA in the SN after MPTP administration. Immunoreactivities for 8-oxoG in SNc (open bars) and SNr (gray bars), as shown in Figure 2Bm, were separately digitized from the data shown in Figure $2 \mathrm{~B}(\mathrm{~m}-\mathrm{p})$, and 8-0xoG index in each sample was determined. The relative value of each 8-0xoG index to that of the control is shown as a bar graph with the means \pm S.D ( $n=4$ per group). Mann-Whitney $U$-test, ${ }^{\star *} P<0.01,{ }^{\star} P<0.05$ compared to the control

Table 1 The contents of 8-oxoG in nuclear DNA prepared from parts of the brains and livers from the control mice and MPTP-treated mice

\begin{tabular}{|c|c|c|c|c|}
\hline \multirow[b]{3}{*}{ Tissues } & \multicolumn{4}{|c|}{$8-O x O G$ per $10^{6}$ guanine residues } \\
\hline & \multicolumn{2}{|c|}{ Control } & \multicolumn{2}{|c|}{ MPTP } \\
\hline & Wild type & MTH1-null & Wild type & MTH1-null \\
\hline $\begin{array}{l}\text { Cerebrum } \\
\text { Cerebellum } \\
\text { Other brain region } \\
\text { Liver }\end{array}$ & $\begin{array}{l}2.54 \pm 0.37 \\
2.76 \pm 0.10 \\
2.79 \pm 0.19 \\
3.02 \pm 0.09\end{array}$ & $\begin{array}{l}2.42 \pm 0.28 \\
2.27 \pm 0.19 \\
3.11 \pm 0.37 \\
2.85 \pm 0.13\end{array}$ & $\begin{array}{l}3.36 \pm 0.23 \\
2.99 \pm 0.16 \\
3.32 \pm 0.22 \\
3.02 \pm 0.26\end{array}$ & $\begin{array}{l}3.42 \pm 0.11 \\
3.17 \pm 0.11 \\
3.99 \pm 0.44 \\
2.85 \pm 0.31\end{array}$ \\
\hline
\end{tabular}

MPTP $(30 \mathrm{mg} / \mathrm{kg}$ ) or saline (control) was administered i.p to wild-type and MTH1-null mice once a day for 5 consecutive days. At 7 days after the last injection, the mice were killed for analyses. Number of mice was five for each group except MTH1-null control $(N=4)$. Nuclear DNA isolated from the tissues were analyzed by HPLCMS/MS to determine the contents of 8-oxoG. Data indicated are the mean \pm S.E.M. There is no significant difference in 8-oxoG levels between wild-type and MTH1null mice (Mann-Whitney $U$-test, $P>0.05$ ). 


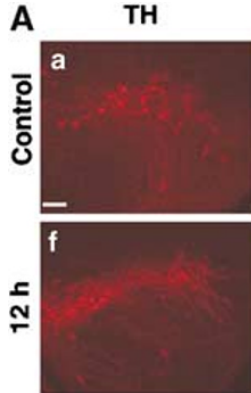

8-OXOG (RNA)
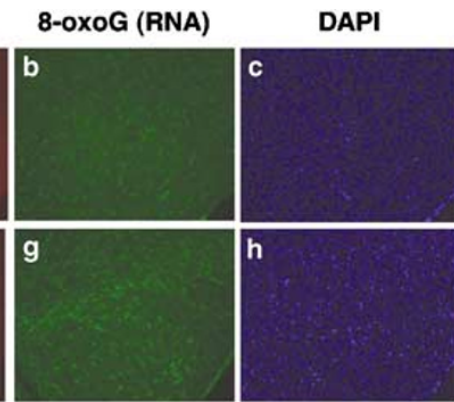

B

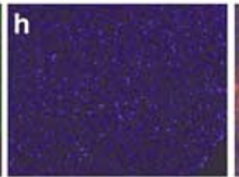

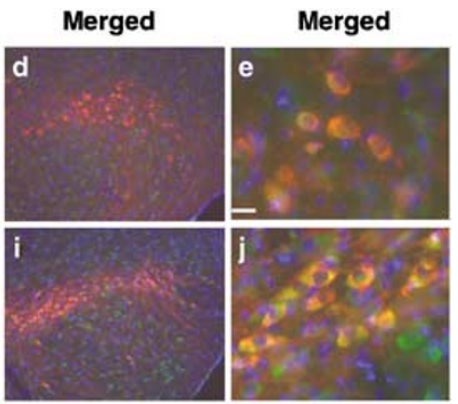
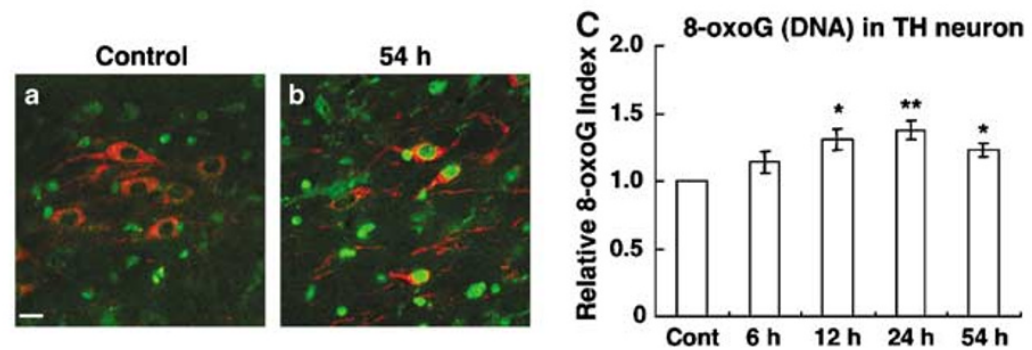

Figure 3 Increased accumulation of 8-0xoG in the nuclear DNA and cellular RNA of dopamine neurons in the substantia nigra after MPTP administration. Animals were treated as in Figure 2A. (A) The localization of 8-0xoG in cellular RNA of the dopamine neurons in the SN determined by fluorescence microscopy. The sections stained for TH (a, f), 8-oxoG in RNA (b, g), and nuclear DNA with DAPI $(c, h)$ are shown. The merged images (d, i); their magnification (e, j). Control (a-e); $12 \mathrm{~h}$ after the first MPTP injection (f-j). Scale bars $(a-d, f-i), 100 \mu \mathrm{m}(e, j), 20 \mu \mathrm{m}$. (B) The localization of 8-oxoG in nuclear DNA of the dopamine neurons in the SNc determined by laser scanning confocal microscopy. The sections were stained for TH (red) and 8-oxoG in nuclear DNA (green), and their merged images are shown. Control (a); $54 \mathrm{~h}$ after the first MPTP injection (b). The nuclear localization of 8-oxoG in the TH-positive neurons was evident after MPTP administration. Scale bar: $10 \mu \mathrm{m}$. (C) The increased accumulation of 8-0xoG in nuclear DNA in the TH-positive dopamine neurons in the SNc after MPTP administration. The immunoreactivities for 8-0xoG in each TH-positive cell were separately digitized from the data shown in Figure 3B, and the 8-oxoG index in each sample was determined. The relative value of each 8-oxoG index to that of the control is shown with the means \pm S.D. ( $n=4$ per group). Mann-Whitney U-test, ${ }^{\star \star} P<0.02,{ }^{\star} P<0.05$ compared to the control

observed (Figure 4Ff). Simultaneously, 8-oxoG immunoreactivitiy in the striatum with RNase pretreatment but not $\mathrm{HCl}$ pretreatment also apparently increased to more than $130 \%$ level of the control (Figure $4 \mathrm{M}, \mathrm{N}, \mathrm{m}, \mathrm{n}$ ), and thereafter decreased (Figure 4O, P, o, p). At $24 \mathrm{~h}$ after the first injection, the terminal dysfunction of dopamine neurons in the NAc and olfactory tubercle (OT) became apparent as well as in the striatum (Figure 4C), and GFAP immunoreactivitiy also increased (Figure $4 \mathrm{I}-\mathrm{K}, \mathrm{i}-\mathrm{k}$ ), thus indicating that astrocytes were activated in the striatum. Next, $54 \mathrm{~h}$ later with three MPTP injections, the terminal dysfunction of dopamine neurons in the striatum, nucleus accumbenes (NAc) and OT was highly prominent (Figure 4D), and accompanied with more activated astrocytes (Figure 4L, I).

As a result, we concluded that the oxidative damage in the nucleic acids of nigrostriatal dopamine neurons is transiently increased during MPTP-induced PD mouse model.

\section{Expression of Mth1 mRNA encoding an oxidized purine nucleoside triphosphatase in normal mouse brain}

We recently showed the accumulation of 8-oxo-dGTP and/or 2-OH-dATP in cellular nucleotide pools to cause cell death, while MTH1 hydrolyzing these oxidized nucleotides to monophosphates efficiently suppresses such cell death. ${ }^{14}$ In order to examine the role of $\mathrm{MTH} 1$ for neuroprotection in damaged brain, we next analyzed the expression of Mth1 mRNA in mouse brain by in situ hybridization. Antisense but not sense probe for Mth1 mRNA exhibited positive signals in neurons throughout brain (Figure $5 \mathrm{Aa}, \mathrm{b}$ ). Neurons in the SN including SNc, SNr and ventral tegmental area (VTA) exhibited substantial levels of Mth1 mRNA expression (Figure $5 \mathrm{Ba}-\mathrm{C})$, as well as neurons in the cerebral cortex and hippocampus (Figure 5Bd-f). The expression of Mth1 mRNA in the brain was confirmed by RT-PCR (data not shown).

A Western blotting analysis revealed the definite expression of MTH1 protein in the striatum of the control and MPTPtreated wild-type mice, and no detectable MTH1 protein in the striatum of either control or MPTP-treated MTH1-null mice (Figure $5 \mathrm{C}$ ). The expression level of $\mathrm{MTH} 1$ protein in the striatum of wild-type mice apparently decreased after MPTP treatment, probably due to the terminal loss of dopamine neurons (Figure 5C, lane 3).

\section{Dopamine neuron loss in SNc induced by MPTP was not affected by MTH1 deficiency}

Given the observed increase of 8-oxoG content in the dopamine neurons in SN after MPTP treatment, we next assessed the neuroprotective role of $\mathrm{MTH} 1$ for the degeneration of dopamine neurons based on a comparison between wild-type and MTH1-null mice. MPTP or saline was administered to wild-type and MTH1-null mice once a day for 5 consecutive days (Figure 6A). The mice were examined for an open field test, rotarod test and the spontaneous basal motor activity in their home cages during the $24 \mathrm{~h}$ circadian cycle. There were no significant differences in the motor activity or 

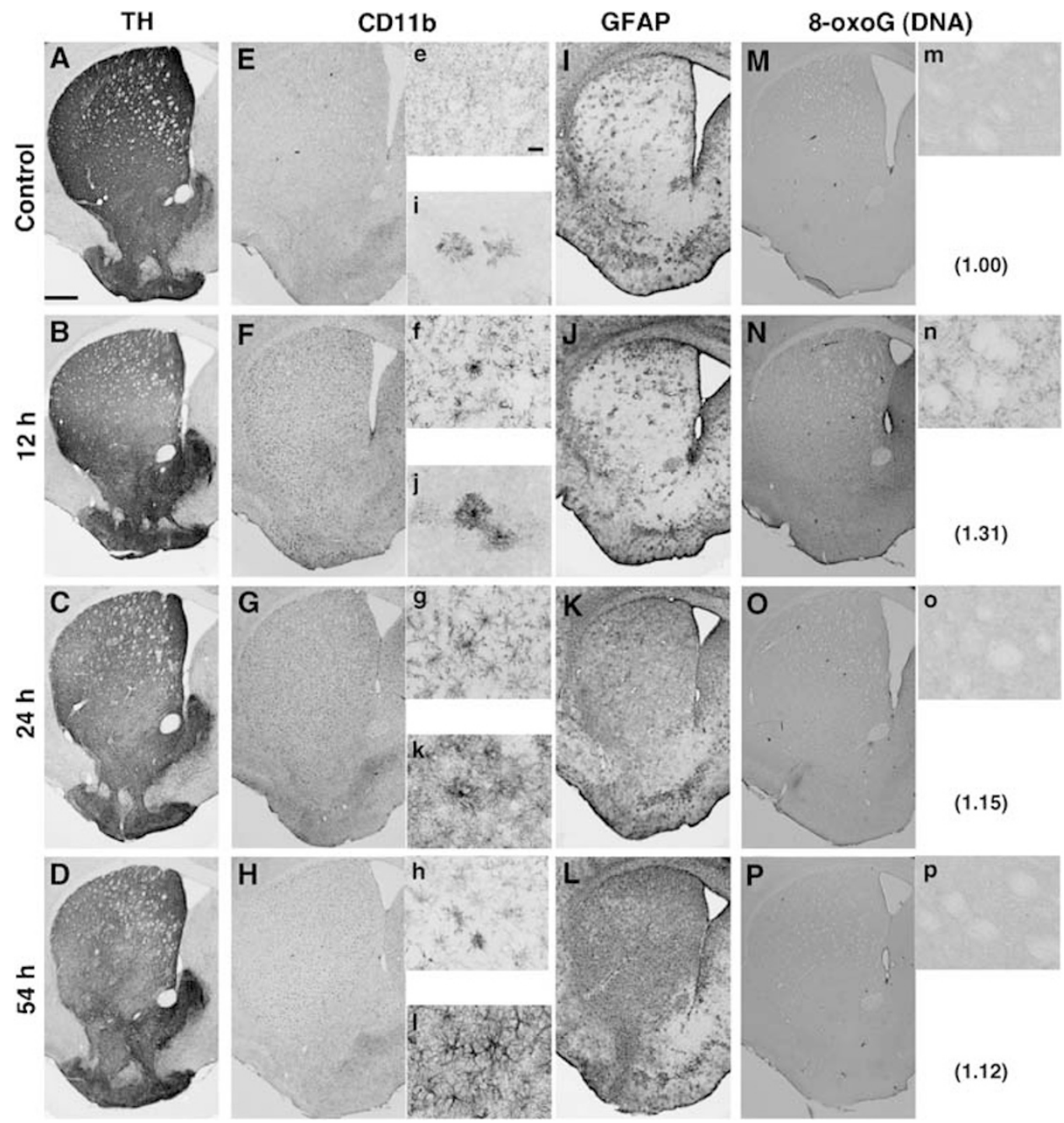

Figure 4 Systemic administration of MPTP transiently increased the accumulation of 8-oxoG in cellular DNA prior to loss of the TH-positive fiber in the striatum. Animals were treated as in Figure 2A. The immunohistochemical detection of TH (A-D), CD11b (E-H, e-h), GFAP (I-L, i-I), and 8-0xoG in DNA (M-P, m-p). The control mice $(\mathbf{A}, \mathbf{E}, \mathrm{e}, \mathbf{I}, \mathrm{i}, \mathbf{M}, \mathbf{m}) ; 12 \mathrm{~h}$ after the first MPTP injection (B, F, f, J, j, N, n); $24 \mathrm{~h}$ after the first injection (C, G, g, K, k, 0, o); $54 \mathrm{~h}$ after the first injection with three injections of MPTP $(\mathbf{D}, \mathbf{H}, \mathrm{h}, \mathbf{L}, \mathrm{I}, \mathbf{P}, \mathrm{p})$. The insets in the panels $(\mathbf{e}-\mathbf{p})$ indicate enlarged view of each section. At $12 \mathrm{~h}$ after the MPTP injection, an increased microglial activation was observed in the striatum $(\mathbf{F}, \mathrm{f})$, and $24 \mathrm{~h}$ after the injection, the loss of TH-positive fiber in the striatum, NAc and the OT became apparent (C), and an increased astrocytes activation was observed in the striatum $(\mathbf{K}, \mathrm{k})$, while the 8-oxoG level transiently increased only $12 \mathrm{~h}$ after the MPTP injection (N, $\mathrm{n}$ ). Relative densities of 8-oxoG immunoreactivitiy to the control (M) are shown in parenthesis. Scale bars (A-P), $500 \mu \mathrm{m} ;(\mathrm{e}-\mathrm{p}), 20 \mu \mathrm{m}$

motor performance between wild-type and MTH1-null mice before and after MPTP administration (data not shown).

At 7 days after the last MPTP or saline injection, the mice were killed and subjected to immunohistochemistry (Figure 6A). The number of $\mathrm{TH}$-positive neurons in the SNc did not differ between the saline-injected wild-type and MTH1null mice (Figure 6Ba, b; 6C). A significant reduction in $\mathrm{TH}$ immunoreactivitiy was apparent in the SN from both wild-type and $\mathrm{MTH} 1$-null mice (Figure $6 \mathrm{Bc}, \mathrm{d}$ ). About $30 \%$ reduction in the number of $\mathrm{TH}$-positive neurons across several levels of the SNc was observed in both wild-type and MTH1-null mice after MPTP treatment, and there was no apparent difference between the two groups (Figure $6 \mathrm{C}$ ). A mild and similar decrease of TH immunoreactivitiy in VTA was also observed in both wild-type and MTH1-null mice after MPTP treatment (Figure 6D).

\section{MTH1-null mice display a more severe reduction of the TH and dopamine transporter (DAT) immunoreactivities in striatal terminal fibers of dopamine neurons after chronic exposure to MPTP}

We next examined whether an MTH1 deficiency would augment the reduction of the TH and DAT immunoreactivities in terminal fibers of dopamine neurons in the striatum induced by chronic MPTP administration (Figure 6A). Either TH, DAT or GFAP immunoreactivitiy in the striatum, NAc and OT did not differ between the saline-injected MTH1-null and wild-type mice (Figure 7A, control).

At 7 days after the last MPTP injection, a significant reduction in $\mathrm{TH}$ immunoreactivitiy in the striatum, NAc, and OT was observed in wild type and the reduction appeared to 
A

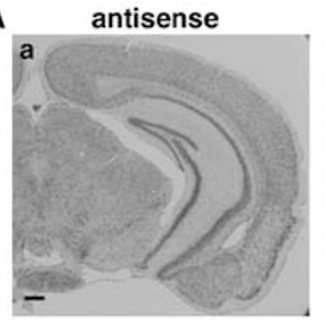

B

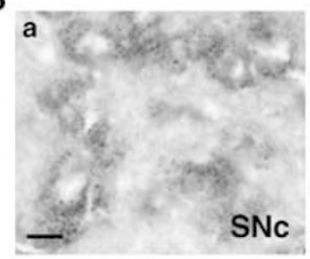

b
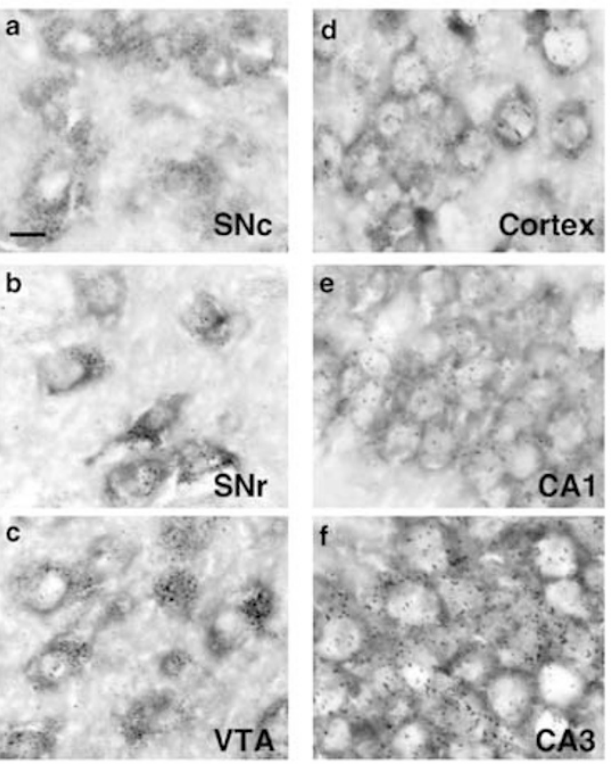

C

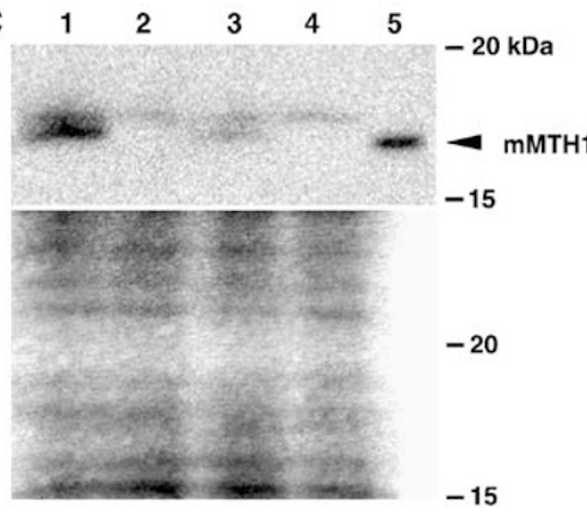

Figure 5 Expression of Mth1 mRNA in the normal mouse brain. (A) The level of Mth1 mRNA in the coronal midbrain sections prepared from the C57BL/6J male mouse was visualized by in situ hybridization with an antisense (a) and sense probe (b). Hybridization signals were detected only with an antisense probe, and they were present in the neurons throughout the brain including the $\mathrm{SN}$ and hippocampus. Scale bar, $500 \mu \mathrm{m}$. (B) Hybridization signals for Mth1 mRNA were present in the neurons of the SNc (a), SNr (b) and VTA (c) as well as in the neurons scattered throughout the cerebral cortex (d), hippocampal CA1 (e) and CA3 subfields (f). Scale bar: $10 \mu \mathrm{m}$. (C) The expression level of MTH1 in the striatum was examined by a Western blot analysis using anti-MTH1 (upper). MPTP (30 mg/kg) or saline was administered i.p to wild-type and MTH1-null mice once a day for 5 consecutive days. At 7 days after the last injection, the lysates (100 $\mu \mathrm{g} /$ lane) prepared from isolated striatum and the recombinant $\mathrm{mMTH} 1$ (10 pg/lane) were subjected to Western blotting. Lane 1, control wild type; lane 2, control MTH1-null mice; lane 3, MPTP-treated wild type; lane 4, MPTP-treated MTH1-null; lane 5, recombinant mMTH1 (10 pg). The same membrane stained with ponceau was shown (lower)

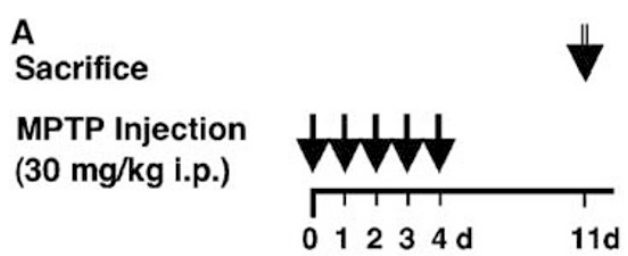

B
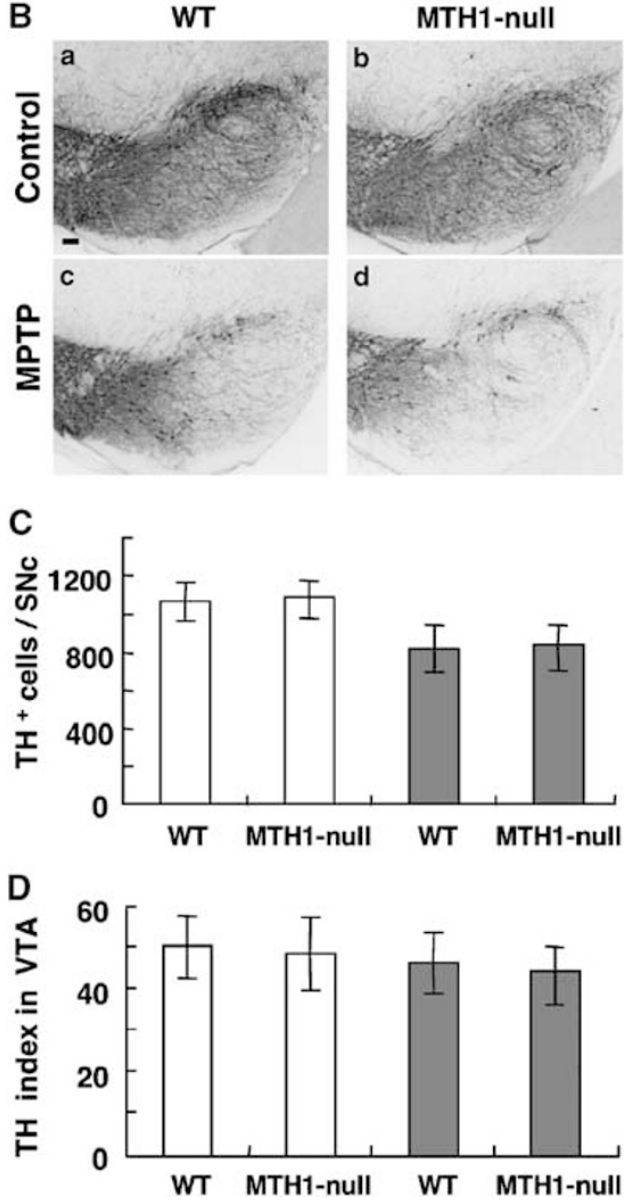

Figure 6 Dopamine neuron loss in the substantia nigra induced by MPTP was not affected by MTH1 deficiency. (A) MPTP $(30 \mathrm{mg} / \mathrm{kg})$ or saline was administered i.p to wild-type and MTH1-null mice once a day for 5 consecutive days. At 7 days after the last injection, the mice were killed for analyses $(n=5$ for each group). (B) Reduction of TH immunoreactivitiy in the SN 7 days after the last MPTP injection. Sections prepared from wild type $(a, c)$ and MTH1-null mice (b, d), after saline (a, b) or MPTP (c, d) injection were subjected to TH immunohistochemistry. A significant reduction of $\mathrm{TH}$ immunoreactivitiy was apparent in the SN from both wild-type and MTH1-null mice after MPTP injection (c, d). Scale bar, $100 \mu \mathrm{m}$. (C) The number of TH-positive neurons in the SNc 7 days after the last MPTP injection decreased by the same degree in both wildtype and MTH1-null mice. The value of the means + S.D. for each group $(n=5)$ is shown as a bar graph without (open bars), or with MPTP treatment (gray bars). (D) A mild and similar decrease of TH immunoreactivitiy in VTA was observed in both wild-type and MTH1-null mice after MPTP treatment. TH immunoreactivities in the VTA were measured in the sections shown in Figure 6B and the TH indexes are shown as a bar graph with a value of means \pm S.D. for each group $(n=5)$ without (open bars), or with MPTP treatment (gray bars)

be more severe in the MTH1-null mice (Figure 7Ai, m). DAT immunoreactivitiy in the three regions also apparently decreased more in the MTH1-null than in the wild-type mice (Figure 7Aj, n). The immunoreactivities for TH and DAT were 
A
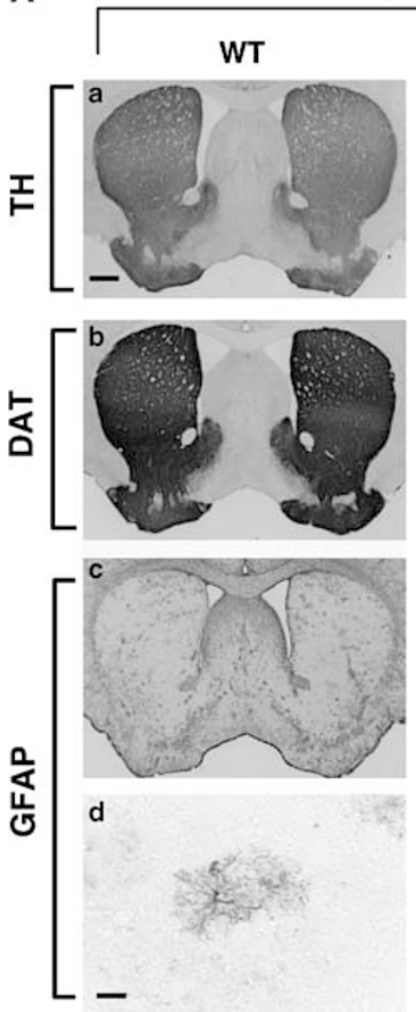

B

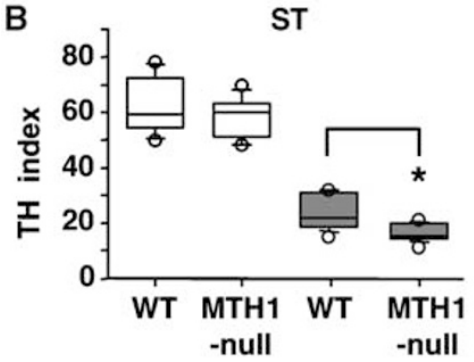

C

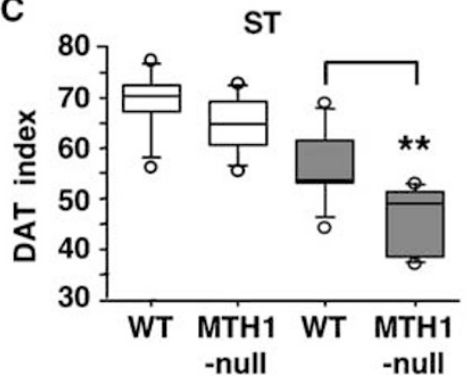

\section{Control}
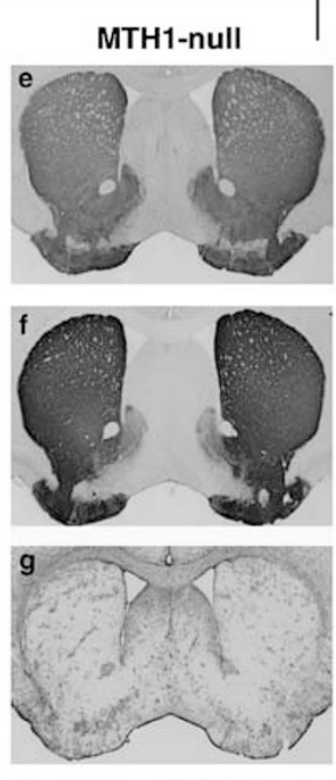

h

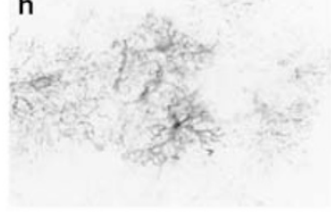

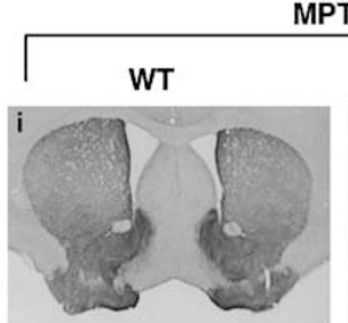
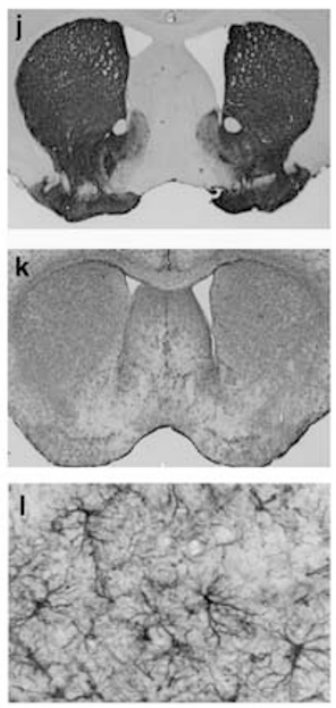

NAC

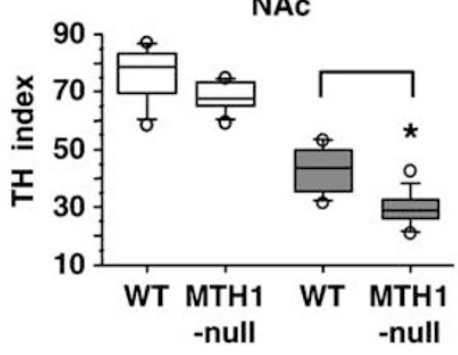

NAc

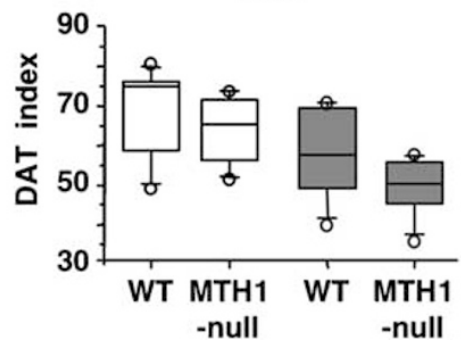

MPTP
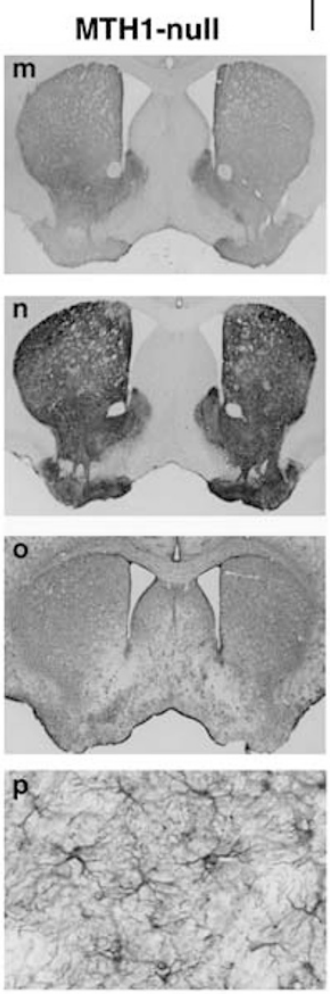

OT

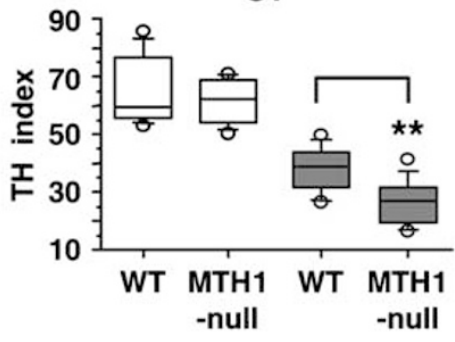

OT

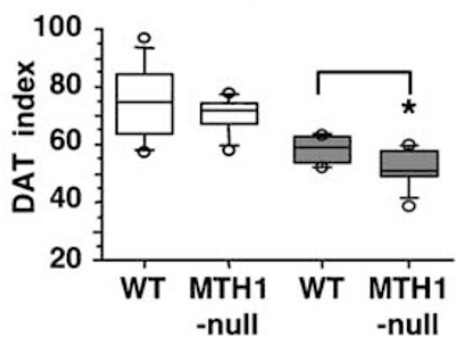

Figure 7 MTH1-null mice display an increased reduction of TH and DAT immunoreactivities in striatal terminal fibers of dopamine neurons after chronic exposure to MPTP. (A) Striatal immunoreactivities for TH, DAT, and GFAP were examined in the sections prepared from the mice administered with saline (Control, a-h) or MPTP (MPTP, i-p), as described in Figure 6A. Wild type $(a-d, i-l)$; MTH1-null mice $(e-h, m-p)$. The magnification of images $(c, g, k, 0)$ are shown $(d, h, i, p)$, respectively. Scale bars (a-c, e-g, i-k, m-0) $500 \mu \mathrm{m}$; (d, h, I, p) $20 \mu \mathrm{m}$. (B) TH immunoreactivities in the striatum, NAc and OT were measured in the sections shown in Figure 7A, and TH indexes are shown in a box and whisker plot $(n=5)$. In each plot, the boxes are drawn with the ends at the quartiles, and the statistical median is shown as a horizontal line in the box. The whiskers extended to the farthest points which are not outliers (circles). TH indexes in striatum, NAc, and OT of MTH1-null mice were significantly lower than those of wild type (WT) after MPTP injection (Mann-Whitney U-test, ${ }^{* \star} P<0.01,{ }^{*} P<0.02$ ). Control, open boxes; MPTP treated, gray boxes. (C) DAT immunoreactivities in the striatum, NAc and OT were measured in the sections shown in Figure 7A, and DAT indexes are shown in a box-and-whisker-plot $(n=4 \sim 5)$, as in B. DAT indexes in striatum and OT of MTH1-null mice were also significantly lower than those of wild type after MPTP injection (Mann-Whitney U-test, ${ }^{\star \star} P<0.01$, ${ }^{*} P<0.05$ 
A
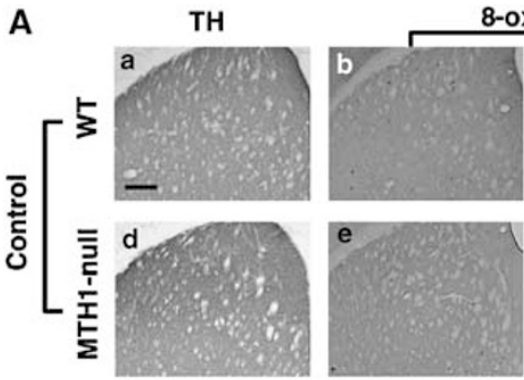

8-oxoG
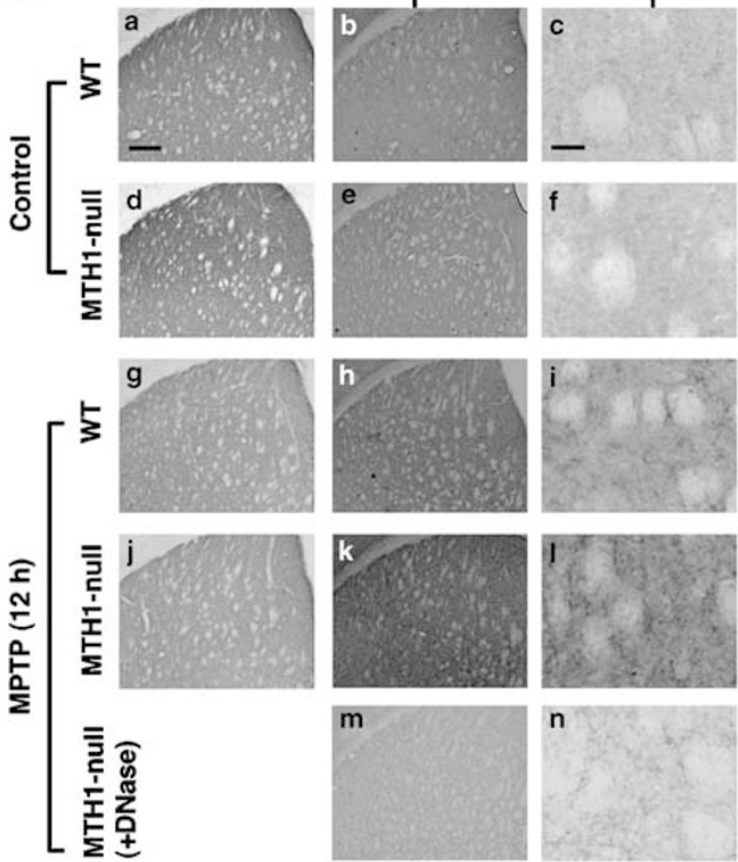

B

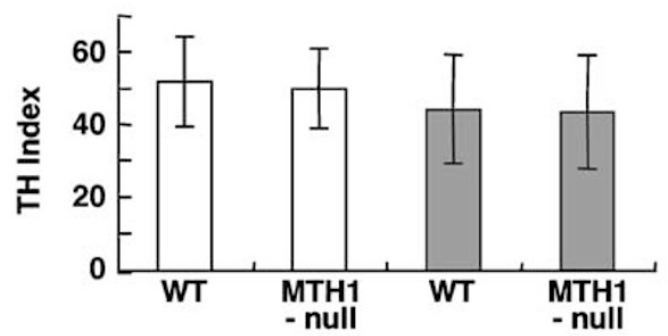

C

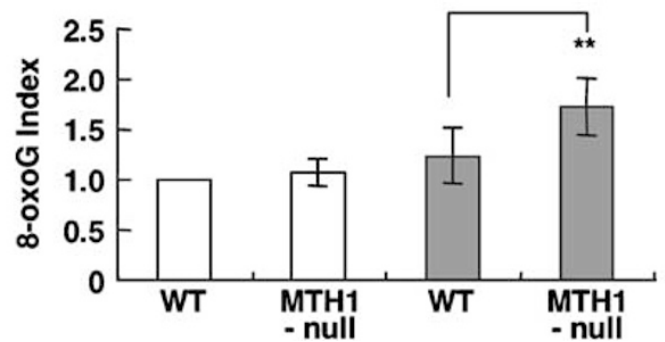

Figure 8 Increased accumulation of 8-oxoG in the striatum of MTH1-null mice after MPTP administration. (A) Striatal immunoreactivities for TH (a, d, g, j) and 8oxoG in DNA (b, $c, e, f, h, i, k, l)$ were examined in the sections prepared $12 \mathrm{~h}$ after the administration of saline (control) or MPTP. To detect 8-0xoG in DNA, the sections were pretreated only with RNase and reacted with the N45.1 mAb. A section was further pretreated with DNase, and then was subjected to the immunohistochemistry using the same antibody $(m, n)$. Wild type (a-c, g-i); MTH1-null mice (d-f, j-n). The magnification of images $(b, e, h, k, m)$ are shown (c, f, i, l, n), respectively. Scale bars (a, b, d, e, g, h, j, k, m) $300 \mu \mathrm{m} ;(\mathrm{c}, \mathrm{f}, \mathrm{i}, \mathrm{l}, \mathrm{n})$ $40 \mu \mathrm{m}$. (B) Immunoreactivities for $\mathrm{TH}$ in the sections shown in Figure $8 \mathrm{~A}$ were digitized, and $\mathrm{TH}$ index in each sample was determined ( $n=4$ per group). The $\mathrm{TH}$ index is shown as a bar graph with the means \pm S.D. Open bar: control; gray bar, MPTP treated. (C) Immunoreactivities for 8-oxoG in the sections shown in Figure $8 \mathrm{~A}$ were digitized, and 8-0xoG index in each sample was determined ( $n=4$ per group). The relative value of each $8-0 \times 0 \mathrm{G}$ index to that of control is shown as a bar graph with the means \pm S.D. Open bar: control; gray bar, MPTP treated. The 8-oxoG index was increased more significantly in MTH1-null mice in comparison to wild type (Mann-Whitney U-test, ${ }^{* \star} P<0.01$ ) digitized and their indexes were compared between the wildtype and MTH1-null mice. TH indexes in striatum, NAc, and OT of MPTP-treated MTH1-null mice were significantly lower than those of the MPTP-treated wild type (Figure 7B). The DAT indexes also decreased significantly more in MPTPtreated MTH1-null mice than in MPTP-treated wild type, especially in the striatum and OT, and to a lesser extent in NAC (Figure 7C).

GFAP immunoreactivitiy in the striatum similarly increased in both the MPTP-treated wild-type and MTH1-null mice, in comparison to the control (Figure 7A, GFAP). There was no significant difference of the GFAP immunoreactivitiy between the MPTP-treated wild-type and MTH1-null mice (data not shown).

These findings indicated that an MTH1 deficiency augments the MPTP-provoked reduction of TH and DAT immunoreactivities in the terminal fibers of dopamine neurons or their dysfunction in the striatum, NAc or OT.

\section{MTH1 deficiency augments the MPTP-induced accumulation of 8-oxoG in the striatum}

To compare the extent of 8-oxoG in cellular DNA in the striatum after MPTP injection in wild-type and MTH1-null mice, the mice were injected with MPTP $(30 \mathrm{mg} / \mathrm{kg})$ and then were killed $12 \mathrm{~h}$ after the injection. At $12 \mathrm{~h}$ after MPTP injection, terminal loss of dopamine neurons was apparent in the striatum of MTH1-null mice at the same degree as that seen in wild type (Figure $8 \mathrm{~A}, \mathrm{TH}$ ). In the same sections, an increase of 8-oxoG immunoreactivitiy in the cellular DNA was observed in the striatum of wild type (Figure 8Ah, i), and the increase was apparently higher in the MTH1-null mice (Figure $8 \mathrm{Ak}, \mathrm{I})$. These immunoreactivities largely decreased after the pretreatment of the sections with DNase (Figure 8Am, n), thus indicating that 8-OxoG in the striatum are mostly in the cytoplasmic DNA, namely, mitochondrial DNA. Immunoreactivities for TH and 8-oxoG in the striatum were digitized, and the level of TH and 8-oxoG in each sample was determined. The TH indexes in striatum of MPTP-treated MTH1-null mice were almost the same level as those of the MPTP-treated wild type (Figure 8B). However, the 8-oxoG indexes in the striatum of the MPTP-treated MTH1-null mice were significantly higher than those of the MPTP-treated wild type (Figure 8C).

Furthermore, we confirmed that the terminal fibers of dopamine neurons in striatum were indeed rich in mitochondria, based on a laser scanning confocal microscopy analysis of TH and cytochrome $C$ in the striatum of wild-type mouse (Figure 9A). Most TH signals in the striatum were largely merged with signals for cytochrome $C$, and spiny neurons in the striatum, which are TH negative, also exhibited intense cytochrom $C$ signals surrounding their nuclei, thus confirming that both TH-positive terminal fibers of dopamine neurons and the postsynaptic spiny neurons are rich in mitochondria. At $12 \mathrm{~h}$ after MPTP injection, strong 8-oxoG immunoreactivities were detected in the striatum of MTH1-null mice but not wild type (Figure 9Ba, f). The 8-oxoG signals exhibited a fiber-like shape and were distributed along with TH-positive fibers, and most of them were colocalized in MTH1-null mice (Figure 9j). It is noteworthy that there was not much 8-oxoG 

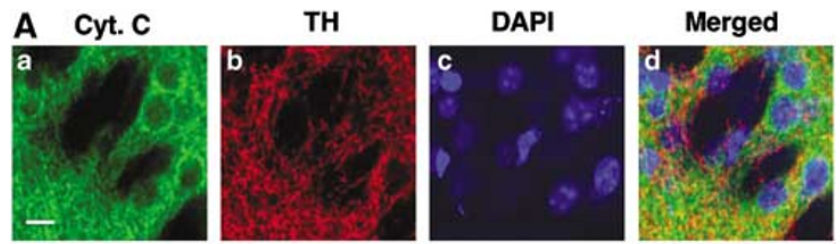

B
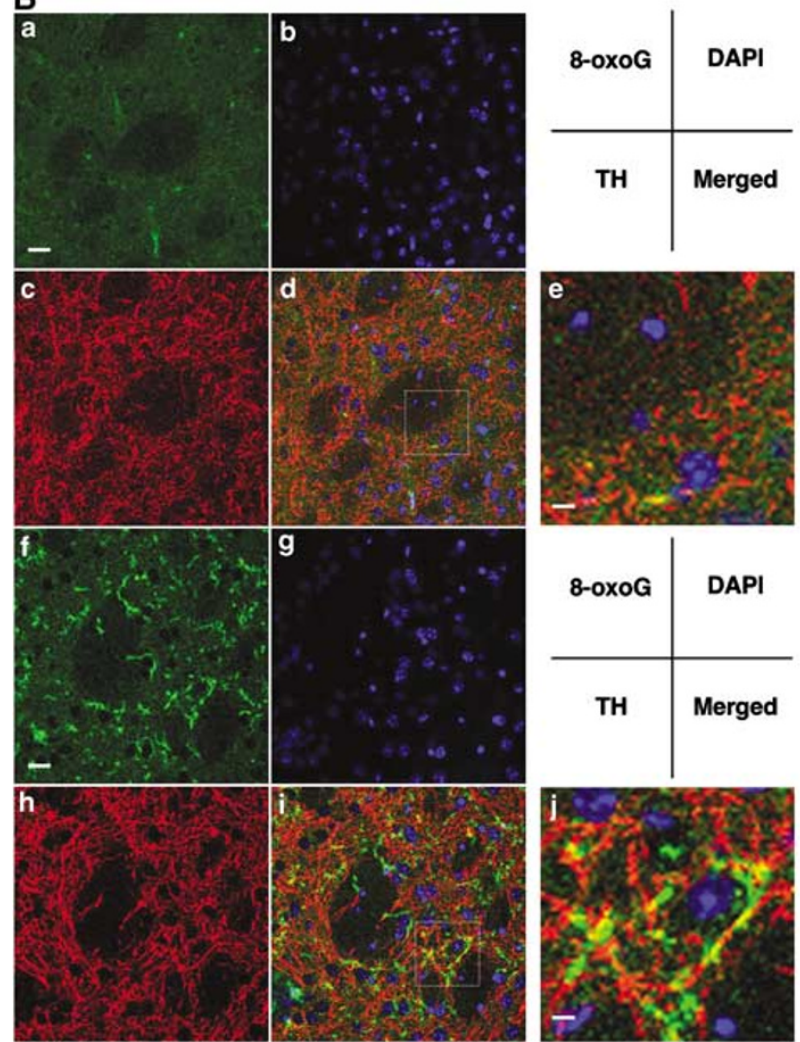

Figure 9 Increased accumulation of 8-0xoG in mitochondrial DNA in the striatal nerve terminals of dopamine neurons in MTH1-null mice after MPTP administration. (A) The localization of cytochrome $C$ in the striatal terminal fibers of dopamine neurons determined by laser scanning confocal microscopy. The sections from wild-type mouse were stained for cytochrome $C$ (Cyt. c) (a), TH (b), nuclear DNA with DAPI (c), and the merged image was shown (d). Scale bar: $10 \mu \mathrm{m}$. (B) The localization of 8-oxoG in the striatal terminal fibers of dopamine neurons determined by laser scanning confocal microscopy. The sections prepared from wild-type (a-e) and MTH1-null mice (f-j) $12 \mathrm{~h}$ after MPTP injection (30 mg/kg, i.p.) were stained for 8-0xoG in DNA with the N45.1 mAb (a, f), nuclear DNA with DAPI $(b, g), T H(c, h)$, and their merged images were shown (d, i). The sections were pretreated only with RNase. Scale bar: $20 \mu \mathrm{m}$. Each part of images shown in dotted box (d, i) was magnified (e, j). Scale bar: $5 \mu \mathrm{m}$

immunoreactivitiy in the cytoplasm of spiny neurons. We thus concluded that 8-oxoG accumulated mostly in the mitochondrial DNA in the striatal nerve terminals of dopamine neurons in the MTH1-null mice $12 \mathrm{~h}$ after MPTP injection.

The HPLC-MS/MS analysis revealed that the contents of 8-oxoG in nuclear DNA prepared from three regions of the brains, especially other brain region that contains striatum, thalamus and brainstem, slightly increased 7 days after the last injection of MPTP, both in wild-type and MTH1-null mice (Table 1). The amounts of 8-oxoG did not increase in the liver from MPTP-treated wild-type and MTH1-null mice.

\section{Discussion}

In the present study, we, for the first time, revealed that the accumulation of oxidized base, 8-oxoG in DNA and RNA in the nigrostriatal dopamine neurons significantly increases during neuronal dysfunction in the mouse brain induced by the systemic administration of MPTP, and furthermore demonstrated that the accumulation of 8-oxoG in the mitochondrial DNA in the terminal fibers of dopamine neurons is one of causes for the neuronal dysfunction of dopamine neurons, which can be minimized by the sanitization of the nucleotide pool by MTH1 with its oxidized purine nucleoside triphosphatase.

MPTP systemically administered is converted to 1-methyl4-phenylpryridinium (MPP ${ }^{+}$), mostly in glial cells, and then $\mathrm{MPP}^{+}$can be specifically taken up by dopamine neurons through DAT. $\mathrm{MPP}^{+}$which accumulates in dopamine neurons binds to complex I of the respiratory chain in mitochondria and blocks the electron transport, thus leading to an energy failure with ATP depletion as well as an increase of electron leakage from the respiratory chain resulting in the formation of free radicals. ${ }^{15,16}$ In addition, dopamine neurons are likely to be exposed to increased levels of oxidative stress caused by the metabolic products of dopamine itself in comparison to the other parts of brain. $\mathrm{MPP}^{+}$also induces a massive release of vesicular dopamine to the cytosol ${ }^{17}$ or an increased dopamine turnover, and it is thus expected that oxidative stress in the dopamine neurons is significantly and specifically increased in such MPTP-administered animals. ${ }^{18,19}$ Furthermore, the oxidation of dopamine stoichiometrically produces hydrogen peroxide which reacts with $\mathrm{Fe}^{2+}$ ion to form hydroxyradical by the Fenton reaction. Hydroxyradical is the most reactive free radicals and it easily oxidizes almost all biomolecules, such as lipids, proteins and nucleic acids, thus resulting in cellular dysfunction or cell death. ${ }^{20,21}$ Since the mitochondrial dysfunction and oxidative stress induced by MPTP are remarkably similar to that seen in the PD brain, ${ }^{22,23}$ studies in genetics and biochemical pathways involved in MPTP toxicity have provided clues to a better understanding of idiopathic PD.

An increased lipid peroxidation and chemical modification of proteins are common features in MPTP-induced PD model, and there has been only one literature reporting that MPTP induces the accumulation of 8-oxoG, an oxidized form of guanine, in the model. ${ }^{24}$ Our present study clearly demonstrated that the accumulation of 8-oxoG in the cellular RNA and DNA significantly increased in SN 12-24 h after a single administration of MPTP, confirming the previous observation, ${ }^{24}$ moreover, we showed that the accumulation of 8 -oxoG was more remarkable in striatum than in SN. Especially, 8oxoG accumulated in the mitochondrial DNA in the striatal nerve terminals of dopamine neurons earlier than the decrease of $\mathrm{TH}$ immunoreactivitiy in the striatum, or earlier than accumulation of 8 -oxoG in cellular RNA or DNA in the $\mathrm{SN}$, where a loss of $\mathrm{TH}$-positive dopamine neurons becomes apparent after the repeated administration of MPTP. These observations strongly suggest that $\mathrm{MPP}^{+}$triggers a degeneration of the dopamine neurons from their terminals in the striatum, in a retrograde manner, as reported previously. ${ }^{25}$ We further observed that microglias and astrocytes were 
significantly activated in striatum or SN 12-24 h after a single administration of MPTP. It has been shown that the activated microglias or astrocytes produce more extracellular superoxide by NADPH oxidase, thus further increasing the oxidative stress in the striatum or $\mathrm{SN}^{26,27}$ In the present study, however, we found that dopamine neuron loss in SNc induced by MPTP was not affected by MTH1 deficiency, that is, only $20 \%$ of dopamine neurons in SNc were lost 7 days after the last MPTP injection both wild-type and MTH1-null mice (Figure 6). Thus, it is likely that the dose of MPTP was not enough to reveal an increased vulnerability of MTH1-null dopamine neurons in the SNc, or it may take much longer time to exhibit their increased vulnerability.

We previously demonstrated that the accumulation of 8oxoG in the mitochondrial DNA of MTH1-null cells induced by hydrogen peroxide treatment results in mitochondrial dysfunction and finally in pyknotic cell death which is independent of general caspases or polyADP-ribose polymerase, but such cell death is very efficiently suppressed by an overexpression of human MTH1. ${ }^{14}$ Since MTH1 possesses an oxidized purine nucleoside triphosphatase activity which efficiently hydrolyzes 2-OH-dATP, 8-oxo-dGTP, 8-oxo-dATP and 2-OH-ATP or 8-oxo-ATP, to a lesser extent 8-oxo-GTP, the disruption of the Mth1 gene must result in the accumulation of these oxidized purine nucleoside triphosphates in the dopamine neurons after MPTP administration. In the present study, we observed that the accumulation of 8-oxoG in the mitochondrial DNA of the terminals of dopamine neurons significantly increased in MTH1-null in comparison to wild-type mice, thus suggesting that various oxidized purine nucleoside triphosphates as well as 8-oxo-dGTP accumulate in the terminals of dopamine neurons and their incorporation into mitochondrial DNA is increased in MTH1-null mice. Furthermore, we showed that an MTH1 deficiency augments the MPTPprovoked reduction of TH and DAT immunoreactivities in the terminal fibers of dopamine neurons in the striatum. These results together strongly suggest that increased levels of various oxidized purine nucleoside triphosphates, including 8-oxo-dGTP, induce a dysfunction of the terminal fibers of dopamine neurons.

Using mutant human MTH1 which hydrolyzes 8-oxo-dGTP but not $2-\mathrm{OH}-\mathrm{dATP}$, or vice versa, we showed that the accumulation of 8-oxo-dGTP and 2-OH-dATP, at least, in the cells results in mitochondrial dysfunction accompanied with electron-dense deposits in the mitochondria, and cell death in murine fibroblasts, ${ }^{14}$ however, it is still unclear as to how the oxidized purine nucleoside triphosphates accumulated or those incorporated into mitochondrial DNA causes such mitochondrial dysfunction and cell death. It has been shown that oxidative damage to mitochondrial DNA increases with age in the human brain, especially in the $\mathrm{SN}$, and it can induce $\mathrm{G}: \mathrm{C}$ to $\mathrm{T}: \mathrm{A}$ and $\mathrm{A}: \mathrm{T}$ to $\mathrm{C}: \mathrm{G}$ transversion mutations, ${ }^{28}$ which are known to be caused by 8 -oxoG or $2-\mathrm{OH}-\mathrm{A},{ }^{1}$ thus suggesting that such mutations in mitochondrial DNA might cause mitochondrial dysfunction. It has been shown that electrondense deposits in the mitochondria are formed in the MPTPinduced PD model, ${ }^{29}$ thus indicating that the induction of mitochondrial dysfunction is one of the major pathways that cause the degeneration of dopamine neurons. We are now trying to identify the signal transduction pathway that triggers cell death following an accumulation of 8-oxo-dGTP or 2-OHdATP in the MTH1-null cells.

In PD patient brains, we found a markedly increased expression of MTH1 accompanied with a significant accumulation of 8-oxoG in the cytoplasm of surviving dopamine neurons in the SN. ${ }^{9}$ Furthermore, we recently also found a highly increased expression of a mitochondrial form of OGG1 (hOGG1-2a) in dopamine neurons in the SN of PD patient brain, thus supporting our hypothesis that 8-oxoG accumulated in mitochondrial DNA is somehow toxic to dopamine neurons. ${ }^{30}$ The present study strongly suggests that the increased expression of MTH1 in the dopamine neurons of PD patients may attenuate their progressive degeneration, and an experimental demonstration of this hypothesis would shed light on the development of new strategies for the therapeutic treatment of PD.

\section{Materials and Methods}

\section{Antibodies}

Mouse N45.1 mAb (1:100), which preferentially recognizes 8-oxoG in DNA, was obtained from JalCA (Fukuroi, Japan), while mouse $15 \mathrm{~A} 3 \mathrm{mAb}$ (1:1200), which recognizes 8-oxoG in both DNA and RNA was obtained from QED Bioscience. To prepare the antibodies preadsorbed by antigen, the N45.1 or 15A3 mAb was mixed with 8-0xo-dG (Sigma) or dG (Yamasa, Japan) at a molar ratio of $1: 100$, and were incubated for $12 \mathrm{~h}$ at $4{ }^{\circ} \mathrm{C}$. Rabbit anti-GFAP polyclonal antibodies $(1: 15000)$ were purchased from Dako. Rabbit anti-TH polyclonal antibodies (1:2000), and rat anti-DAT mAb $(1: 8000)$ (DAT-Nt, MAB369) were obtained from Chemicon. Rat mAb, MAC-1 $(1: 100)$ against mouse CD11b was obtained from Serotec. Rabbit anti-VDAC polyclonal antibodies were described previously. ${ }^{31}$ Mouse anticytochrome $C$ mAb (1:500) was purchased from BD Biosciences. Alexa Fluor-labeled second antibodies were obtained from Invitrogen.

\section{Animals}

We previously established Mth1 gene-knockout mice. ${ }^{13}$ Heterozygous mice $\left(\right.$ Mth ${ }^{+/}$) backcrossed to C57BL/6J (Clea Japan Inc., Tokyo, Japan) for more than 12 generations were maintained, thereby ensuring a standard C57BL/6J genetic background. ${ }^{32}$ In the present study, the C57BL/6J strain was considered to be a wild-type mouse. MTH1-null $\left(M t h 1^{-/}\right)$mice obtained by the mating of the heterozygous Mth $1^{+/-}$mice were bred only one generation to yield MTH1-null offsprings for the experiments. Animals were maintained in an air-conditioned, light timecontrolled, specific-pathogen-free room. The handling and killing of all animals were carried out in accordance with the national prescribed guidelines, and ethical approval for the studies was granted by the Animal Experiment Committee of Kyushu University.

\section{Experimental design and MPTP treatment}

Male mice (10-12 weeks old) were used for this study. Mice were injected i.p. once a day for 5 consecutive days, with either saline (vehicle) or MPTP-HCl (30 mg/kg free base, Sigma) dissolved in saline. To analyze the acute phase response after MPTP administration, mice were killed at various time points, ranging $0,6,12,24 \mathrm{~h}$ after the first injection on the day 0 , and $6 \mathrm{~h}$ after the third injection on the day 2. To analyze the chronic effects of MPTP, mice were killed 7 days after the fifth injection on the 
day 4. Each experimental design is shown in Figure $2 \mathrm{~A}$ and Figure $6 \mathrm{~A}$, respectively.

\section{Tissue processing}

Animals deeply anesthetized with pentobarbital (30 mg/kg i.p.), were perfused intracardially with saline followed by cold $4 \%$ paraformaldehyde (PFA) in $0.1 \mathrm{M}$ PBS. The brains were removed, immersed for $12 \mathrm{~h}$ in the same $4 \%$ PFA fixative at $4{ }^{\circ} \mathrm{C}$, and cryoprotected in $20 \%, 30 \%$ sucrose in PBS for $48 \mathrm{~h}$ at $4^{\circ} \mathrm{C}$. The brains were then frozen and stored at $-80^{\circ} \mathrm{C}$ until use. Serial coronal sections (40 $\mu$ m thickness) were cut on a cryostat, collected as free-floating sections in PBS or PBS-T (Triton X, $0.3 \%$ ), and processed immediately for immunohistochemistry. Coronal sections (10 $\mu \mathrm{m}$ thickness) were cut on a cryostat, and then were mounted on slides and stored at $-80^{\circ} \mathrm{C}$ until they were used for in situ hybridization.

\section{Pretreatment of free-floating section for detection of 8-oxoG}

To detect 8-OxOG in RNA, free-floating sections were directly subjected to immunohistochemistry with the $15 \mathrm{~A} 3 \mathrm{mAb}$, without any pretreatment. To eliminate cellular RNA, the sections were incubated in $10 \mathrm{mM}$ Tris- $\mathrm{HCl}$ (pH7.5), $15 \mathrm{mM} \mathrm{NaCl}$ containing DNase-free RNase $(5 \mathrm{mg} / \mathrm{ml}$ of heatinactivated RNase A, Sigma) for $60 \mathrm{~min}$ at $37^{\circ} \mathrm{C}$, prior to incubation with a proper primary antibody. To detect 8-0xoG in cellular DNA other than nuclear DNA, the RNase-treated sections were directly subjected to immunohistochemistry with the N45.1 mAb. To detect 8-0xoG in nuclear DNA, the RNase-treated sections were further treated with $3 \mathrm{~N} \mathrm{HCl}$ at room temperature for $30 \mathrm{~min}$, thus denaturing the nuclear DNA, and then sections were subjected to immunohistochemistry with the N45.1 mAb. To eliminate cellular DNA, the sections were incubated in $50 \mathrm{mM}$ Tris- $\mathrm{HCl}$ (pH7.5), $0.1 \mathrm{mM} \mathrm{MgCl}$ containing RNase-free DNase I $(1000 \mathrm{U} / \mathrm{ml}$, Sigma) for $60 \mathrm{~min}$ at $37^{\circ} \mathrm{C}$, following incubation with DNase-free RNase.

\section{Immunohistochemistry}

Free-floating sections with an appropriate pretreatment were incubated in Block Ace, (Dainippon Pharmaceutical, Japan) for $30 \mathrm{~min}$ at room temperature, and then were incubated with each appropriately diluted primary antibody in $10 \%$ Block Ace, at $4{ }^{\circ} \mathrm{C}$ overnight. The rinsed sections were immersed in a solution of $3 \% \mathrm{H}_{2} \mathrm{O}_{2}$ in methanol/PBS $(1: 1)$ for $5 \mathrm{~min}$ at root temperature, and then were processed by Vectastain $A B C$ kit (Vector Labo.) with a proper biotinylated secondary antibody, and the peroxidase reaction product was detected using $3^{\prime} 3^{\prime}$-diaminobenzidinetetrahydrochloride (DAB, Vector). All sections were then washed in PBS, mounted on slides, and coverslipped. Digital images were acquired using Axioskop2 plus equipped with a CCD camera, AxioCam (Carl Zeiss), or using LeicaZoom2000 (Leica Mycrosystems) equipped with a digital camera, Cyber-shot (Sony, Japan). In order to ensure the quantitative measurement of each immunoreactivitiy, all sections from each experimental animal and group to be compared were processed in parallel by immunohistochemistry.

\section{Laser scanning confocal microscopy}

Free-floating sections incubated with a proper primary antibody were further incubated with a proper Alexa Fluor-labeled second antibody for $45 \mathrm{~min}$ at room temperature. The sections were incubated in a solution containing DAPI $(0.05 \mu \mathrm{g} / \mathrm{ml}$, Sigma) for $10 \mathrm{~min}$ at room temperature, and mounted on slides with Vectashield (Vector). Confocal images were acquired under Eclipse TE300 (Nikon, Japan) equipped with the Radiance 2100 laser scanning confocal microscope system (Bio-Rad Labo.), or under LSM 510 META (Carl Zeiss). All sections from each experimental animal and group to be compared were processed in parallel.

\section{Quantitative morphometric analysis}

All acquired digital images were processed uniformly at a threshold in a gray scale mode to subtract any background corresponding to the area without tissue by Adobe Photoshop version 5.5 (Adobe Systems). The OD of each immunoreactivitiy in a given area for 8-0xoG, TH, DAT, GFAP, respectively, was measured using the Image Gauge version 3.2 (FUJIFILM, Japan). From each individual animal, four representative sections were measured and the mean $\mathrm{OD}$ was calculated as an immunoreactivitiy index for each animal. The number of dopamine neurons in the SNc was estimated by counting all TH-positive neurons of two hemispheres from five coronal sections ( $40 \mu \mathrm{m}$ thick) per animal that were distributed every $120 \mu \mathrm{m}$ along the rostral-caudate axis of the SN $\left(-3.08\right.$ to $-3.64 \mathrm{~mm}$ caudal to bregma). ${ }^{33}$ In order to quantitate 8-0xoG immunoreactivitiy in $\mathrm{TH}$-positive neurons in $\mathrm{SNc}$, fluorescent signals for 8oxoG in nuclear DNA of the TH-positive neurons were selectively extracted from the confocal images for $\mathrm{TH}$ and 8-0xoG immunofluorescence, using the Adobe Photoshop. The OD of fluorescent signals for 8-oxoG were measured by using Image Gauge. In all, 15-30 TH-positive neurons in five sections from each animal were analyzed, and the mean OD was calculated as 8-oxoG index per a $\mathrm{TH}$-positive neuron for each animal. All quantitative analyses were performed by an individual unaware of the experimental treatments.

\section{In situ hybridization of mouse Mth1 mRNA}

A digoxigenin-labeled single-stranded RNA probe was prepared using the Digoxigenin RNA Labeling Kit (Roche), according to the manufacturer's instructions. pGEM-3Zf plasmid (Promega) carrying mouse Mth1 cDNA was transcribed with SP6 or T7 RNA polymerase in the presence of digoxigenin-labeled UTP (Roche) to obtain the sense and antisense riboprobes. In situ hybridization was performed using the Ventana Discovery instrument (Ventana Medical Systems) according to the manufacturer's instructions. The sections were incubated with alkaline phosphatase-conjugated antidigoxigenin antibody (1:500, Roche). Alkaline phosphatase reaction product was detected using 5-bromo-4-chloro3-indolyl phosphate/nitro blue tetrazolium (Sigma).

\section{Western blotting}

The brain samples were homogenized at $4^{\circ} \mathrm{C}$ in five volumes of lysis buffer containing $50 \mathrm{mM}$ Tris- $\mathrm{HCl} \mathrm{pH} 8.0,150 \mathrm{mM} \mathrm{NaCl}, 0.5 \%$ sodium deoxycholate, $1 \%$ NP40, $0.1 \%$ SDS, and protease inhibitor cocktail (Nacalai Tesque, Japan), followed by sonication. The brain lysates were subjected to SDS-PAGE (15\%) followed by Western blotting using antiMTH1 $(3.0 \mu \mathrm{g} / \mathrm{ml}),{ }^{34}$ according to a previously described method. ${ }^{35}$ After blotting, the membrane was incubated with $0.5 \%$ ponceau S (MP Biomedical, Germany) to quantitate the amount of protein on the membrane. Recombinant mouse MTH1 (mMTH1) expressed in E. coli BL21 cells carrying pET3a: mMTH1 was used as a standard.

\section{HPLC-MS/MS analysis}

The nuclear DNA was prepared from the tissue specimens and were subjected to an HPLC-MS/MS analysis of 8-oxoG, according to a 
previously described method. ${ }^{36}$ Brain was separated to three regions, cerebrum, cerebellum and other brain region that contains striatum, thalamus and brainstem, prior to DNA extraction.

\section{Acknowledgements}

We thank Drs. Yasuhide Mitsumoto, Masami Nakai, Daisuke Tsuchimoto for their helpful discussions, Setsuko Kitamura, Naomi Adachi, Akemi Matsuyama and Keiko Aiura for their technical assistance, Dr. Jun-ichi Kira for providing us with the opportunity to conduct this study, Dr. B Quinn for comments on the manuscript. This work was supported by grants from CREST, Japan Science and Technology Agency, the Ministry of Education, Culture, Sports, Science, and Technology of Japan (Grant number: 16012248), and the Japan Society for the Promotion of Science (Grant numbers: 15590347, 16390119).

\section{References}

1. Nakabeppu Y, Tsuchimoto D, Furuichi M and Sakumi K (2004) The defense mechanisms in mammalian cells against oxidative damage in nucleic acids and their involvement in the suppression of mutagenesis and cell death. Free Radic. Res. 38: 423-429

2. Sekiguchi $M$ and Tsuzuki $T$ (2002) Oxidative nucleotide damage: consequences and prevention. Oncogene 21: 8895-8904

3. Nakabeppu Y (2001) Molecular genetics and structural biology of human MutT homolog, MTH1. Mutat. Res. 477: 59-70

4. Nakabeppu Y, Tsuchimoto D, Ichinoe A, Ohno M, Ide Y, Hirano S, Yoshimura D, Tominaga Y, Furuichi M and Sakumi K (2004) Biological significance of the defense mechanisms against oxidative damage in nucleic acids caused by reactive oxygen species: from mitochondria to nuclei. Ann. NY Acad. Sci. 1011: 101-112

5. Shigenaga MK, Hagen TM and Ames BN (1994) Oxidative damage and mitochondrial decay in aging. Proc. Natl. Acad. Sci. USA 91: 10771-10778

6. Kasai $\mathrm{H}$ and Nishimura S (1984) Hydroxylation of deoxyguanosine at the C-8 position by ascorbic acid and other reducing agents. Nuc. Acids Res. 12: 21372145

7. lida T, Furuta A, Kawashima M, Nishida J, Nakabeppu Y and Iwaki T (2001) Accumulation of 8-oxo-2'-deoxyguanosine and increased expression of hMTH1 protein in brain tumors. Neuro-oncol 3: 73-81

8. Zhang J, Perry G, Smith MA, Robertson D, Olson SJ, Graham DG and Montine TJ (1999) Parkinson's disease is associated with oxidative damage to cytoplasmic DNA and RNA in substantia nigra neurons. Am. J. Pathol. 154: 1423-1429

9. Shimura-Miura H, Hattori N, Kang D, Miyako K, Nakabeppu $Y$ and Mizuno $Y$ (1999) Increased 8-oxo-dGTPase in the mitochondria of substantia nigral neurons in Parkinson's disease. Ann. Neurol. 46: 920-924

10. Nunomura A, Perry G, Aliev G, Hirai K, Takeda A, Balraj EK, Jones PK, Ghanbari H, Wataya T, Shimohama S, Chiba S, Atwood CS, Petersen RB and Smith MA (2001) Oxidative damage is the earliest event in Alzheimer disease. J. Neuropathol. Exp. Neurol. 60: 759-767

11. Kikuchi H, Furuta A, Nishioka K, Suzuki SO, Nakabeppu Y and Iwaki T (2002) Impairment of mitochondrial DNA repair enzymes against accumulation of 8oxo-guanine in the spinal motor neurons of amyotrophic lateral sclerosis. Acta. Neuropathol. 103: 408-414

12. Furuta A, lida T, Nakabeppu Y and Iwaki T (2001) Expression of hMTH1 in the hippocampi of control and Alzheimer's disease. Neuroreport 12: 2895-2899

13. Tsuzuki T, Egashira A, Igarashi $H$, Iwakuma $T$, Nakatsuru $Y$, Tominaga $Y$, Kawate H, Nakao K, Nakamura K, Ide F, Kura S, Nakabeppu Y, Katsuki M, Ishikawa T and Sekiguchi M (2001) Spontaneous tumorigenesis in mice defective in the MTH1 gene encoding 8-oxo-dGTPase. Proc. Natl. Acad. Sci. USA 98: 11456-11461

14. Yoshimura D, Sakumi K, Ohno M, Sakai Y, Furuichi M, Iwai S and Nakabeppu Y (2003) An oxidized purine nucleoside triphosphatase, MTH1, suppresses cell death caused by oxidative stress. J. Biol. Chem. 278: 37965-37973

15. Nicklas WJ, Vyas I and Heikkila RE (1985) Inhibition of NADH-linked oxidation in brain mitochondria by 1-methyl-4-phenyl-pyridine, a metabolite of the neurotoxin, 1-methyl-4-phenyl-1,2,5,6-tetrahydropyridine. Life Sci. 36: 25032508

16. Ramsay RR, Krueger MJ, Youngster SK, Gluck MR, Casida JE and Singer TP (1991) Interaction of 1-methyl-4-phenylpyridinium ion (MPP+) and its analogs with the rotenone/piericidin binding site of NADH dehydrogenase. J. Neurochem. 56: 1184-1190

17. Lotharius $\mathrm{J}$ and O'Malley $\mathrm{KL}$ (2000) The parkinsonism-inducing drug 1-methyl4-phenylpyridinium triggers intracellular dopamine oxidation. A novel mechanism of toxicity. J. Biol. Chem. 275: 38581-38588

18. Schmidt $N$ and Ferger $B$ (2001) Neurochemical findings in the MPTP model of Parkinson's disease. J. Neural Transm. 108: 1263-1282

19. Przedborski S and Vila M (2003) The 1-methyl-4-phenyl-1,2,3,6tetrahydropyridine mouse model: a tool to explore the pathogenesis of Parkinson's disease. Ann. NY Acad. Sci. 991: 189-198

20. Karam LR, Bergtold DS and Simic MG (1991) Biomarkers of $\mathrm{OH}$ radical damage in vivo. Free Radic. Res. Commun. 12-13 (Part 1): 11-16

21. Halliwell B (1992) Reactive oxygen species and the central nervous system. J. Neurochem. 59: 1609-1623

22. Schapira AH (1997) Mitochondrial dysfunction and oxidative damage in Parkinon's disease In Mitochondria and Free Radicals in Neurodegenarative Diseases Beal M, Howell N and Bódis-Wollner I (eds) (New York: Wiley-Liss Inc.) pp. 343-359

23. Mizuno Y, Yoshino H, lkebe S, Hattori N, Kobayashi T, Shimoda-Matsubayashi S, Matsumine $\mathrm{H}$ and Kondo T (1998) Mitochondrial dysfunction in Parkinson's disease. Ann. Neurol. 44: S99-S109

24. Chen L-J, Gao Y-Q, Li X-J, Shen D-H and Sun F-Y (2005) Melatonin protects against MPTP/MPP+-induced mitochondrial DNA oxidative damage in vivo and invitro. J. Pineal Res. 39: 34-42

25. Nakai M, Mori A, Watanabe A and Mitsumoto $Y$ (2003) 1-methyl-4phenylpyridinium $\left(\mathrm{MPP}^{+}\right)$decreases mitochondrial oxidation-reduction (REDOX) activity and membrane potential $\left(\Delta \psi_{\mathrm{m}}\right)$ in rat striatum. Exp. Neurol. 179: 103-110

26. Czlonkowska A, Kohutnicka M, Kurkowska-Jastrzebska I and Czlonkowski A (1996) Microglial reaction in MPTP (1-methyl-4-phenyl-1,2,3,6-tetrahydropyridine) induced Parkinson's disease mice model. Neurodegeneration 5: 137-143

27. Kurkowska-Jastrzebska I, Wronska $A$, Kohutnicka M, Czlonkowski $A$ and Czlonkowska A (1999) The inflammatory reaction following 1-methyl-4-phenyl1,2,3, 6-tetrahydropyridine intoxication in mouse. Exp. Neurol. 156: 50-61

28. Simon DK, Lin MT, Zheng L, Liu GJ, Ahn CH, Kim LM, Mauck WM, Twu F, Beal MF and Johns DR (2004) Somatic mitochondrial DNA mutations in cortex and substantia nigra in aging and Parkinson's disease. Neurobiol. Aging 25: 71-81

29. Song DD, Shults CW, Sisk A, Rockenstein E and Masliah E (2004) Enhanced substantia nigra mitochondrial pathology in human alpha-synuclein transgenic mice after treatment with MPTP. Exp. Neurol. 186: 158-172

30. Fukae J, Takanashi M, Kubo S-i, Nishioka K-i, Nakabeppu Y, Mori H, Mizuno Y and Hattori N (2005) Expression of 8-oxoguanine DNA glycosylase (OGG1) in Parkinson's disease and related neurodegenerative disorders. Acta Neurophathol. 109: 256-262

31. Alam TI, Kanki T, Muta T, Ukaji K, Abe Y, Nakayama H, Takio K, Hamasaki $\mathrm{N}$ and Kang D (2003) Human mitochondrial DNA is packaged with TFAM. Nuc. Acids Res. 31: 1640-1645

32. Sakumi K, Tominaga $Y$, Furuichi M, Xu P, Tsuzuki T, Sekiguchi $M$ and Nakabeppu $Y$ (2003) Ogg1 knockout-associated lung tumorigenesis and its suppression by Mth1 gene disruption. Cancer Res. 63: 902-905

33. Franklin KB and Paxinos G (2001) The Mouse Brain in Stereotaxic Coordinates (New York: Academic Press)

34. Kakuma T, Nishida J, Tsuzuki T and Sekiguchi M (1995) Mouse MTH1 protein with 8-oxo-7,8-dihydro-2'-deoxyguanosine $5^{\prime}$-triphosphatase activity that prevents transversion mutation. CDNA cloning and tissue distribution. J. Biol. Chem. 270: 25942-25948

35. Tsuchimoto D, Sakai Y, Sakumi K, Nishioka K, Sasaki M, Fujiwara T and Nakabeppu Y (2001) Human APE2 protein is mostly localized in the nuclei and to some extent in the mitochondria, while nuclear APE2 is partly associated with proliferating cell nuclear antigen. Nuc. Acids Res. 29: 2349-2360

36. Tsuruya K, Furuichi M, Tominaga $Y$, Shinozaki M, Tokumoto M, Yoshimitsu T, Fukuda K, Kanai H, Hirakata H, lida M and Nakabeppu Y (2003) Accumulation of 8-oxoguanine in the cellular DNA and the alteration of the OGG1 expression during ischemia-reperfusion injury in the rat kidney. DNA Repair 2: 211-229 